\title{
Production and Dry Mechanochemical Activation of Biochars Derived from Moroccan Red Macroalgae Residue and Olive Pomace Biomass for Treating Wastewater: Thermodynamic, Isotherm, and Kinetic Studies
}

Saida Tayibi, Florian Monlau, Nour-Elhouda Fayoud, Emna Abdeljaoued, Hassane Hannache, Youssef Zeroual, Abdallah Oukarroum, and Abdellatif Barakat*

Cite This: ACS Omega 2021, 6, 159-171

Read Online

ABSTRACT: This study aimed to produce activated biochars (BCs) from Moroccan algae residue $(A G)$ and olive pomace (OP) using mechanochemical activation with $\mathrm{NaOH}$ and ball milling $(\mathrm{BM})$ for treating artificial textile wastewater containing methylene blue $(\mathrm{MeB})$. The produced OP-activated $\mathrm{BC}$ by $\mathrm{BM}$ showed the highest absolute value of $\zeta$-potential $(-59.7 \mathrm{mV})$ and high removal efficiency of $\mathrm{MeB}$ compared to other activated BCs. The nonlinear pseudo-first-order kinetic model was the most suitable model to describe the kinetics of adsorption of $\mathrm{MeB}$ onto biochars produced from $\mathrm{AG}$ and the $\mathrm{NaOH}$-activated $\mathrm{BC}$ from $\mathrm{OP}$, whereas the nonlinear pseudo-second-order kinetic model suits the OP raw biochar and BM-activated BC. The nonlinear Langmuir isotherm model was the most suitable model for describing $\mathrm{MeB}$ adsorption onto BCs, compared to the nonlinear Freundlich isotherm model. The maximum adsorption capacities of AG-activated $\mathrm{BCs}$ with $\mathrm{NaOH}$ and $\mathrm{BM}$ were 13.1 and $9.1 \mathrm{mg} / \mathrm{g}$, respectively, while those of OP-activated BCs were 2.6 and 31.8

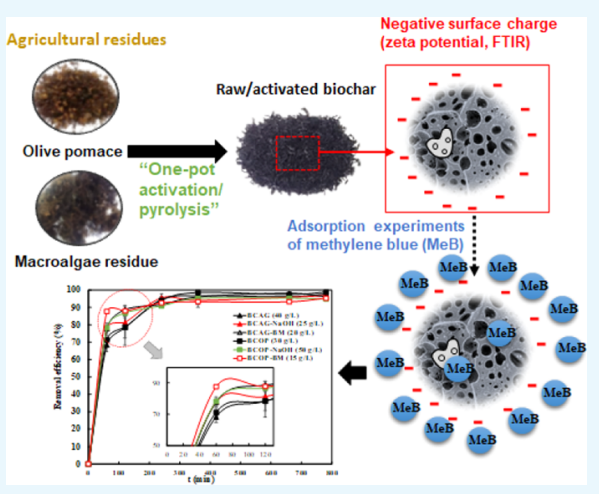
$\mathrm{mg} / \mathrm{g}$, respectively. The thermodynamic study indicates the spontaneous and endothermic nature of the adsorption process of most activated BCs. In addition, $\Delta S^{\circ}$ values indicate the increase of randomness at the solid-liquid interface during MeB sorption onto BC.

\section{INTRODUCTION}

Today, in the industrial society, dyes are used in various industrial domains and have become indispensable in any marketing. ${ }^{1}$ However, it has been reported that organic dyes are harmful to the environment ${ }^{2,3}$ and humans due to their carcinogenic, teratogenic, and mutagenic effects. ${ }^{1}$ The removal of organic dyes has been studied in recent decades using various technologies, such as membrane filtration, ${ }^{4}$ adsorption, ${ }^{2}$ and photocatalytic degradation. ${ }^{5}$ Among these various technologies, the adsorption process using carbonaceous materials [such as biochar (BC) or activated biochar] is considered one of the most practical technologies for removing dyes from wastewater because of its lower cost, simplicity of design, and operation, and it does not require high operating temperature or pressure. ${ }^{6}$

The attractiveness of agroindustrial residues has increased in recent years due to their renewal and their ability to be used as precursors for the development of new value-added products by extraction and biological or thermochemical processes (i.e., bioadsorbents, biofertilizers). ${ }^{7}$ Among thermochemical conversion processes, slow pyrolysis is one of the most conventional types of pyrolysis that has been used specifically for biochar (BC) production. ${ }^{8}$ In parallel, slow pyrolysis also produces bio-oil and syngas that can be used as energy carriers, thus contributing to energy self-sufficiency of the overall system. BCs have been used in environmental ${ }^{9}$ and energy ${ }^{10}$ fields and have also attracted attention as a potential adsorbent of organic and inorganic pollutants due to their low-cost production technology compared to activated carbon. ${ }^{11}$ Nevertheless, to manage the high efficiency of activated carbon, several types of activations, including chemical, mechanical, and biological, have been studied in recent decades. However, it is important to emphasize that the effect of activation on $\mathrm{BC}$ depends mainly on the nature and structure of raw material and on the activation methods. ${ }^{12}$ Until now, chemical and mechanical activations have been frequently applied to enhance the adsorption performances of carbonaceous materials. ${ }^{13-15}$ Chemical activation of the raw biomass using alkaline catalysts enhanced the physicochemical properties and then improved the removal rate by generating porosity and introducing new functional groups onto the surface

Received: August 19, 2020

Accepted: December 3, 2020

Published: December 21, 2020 

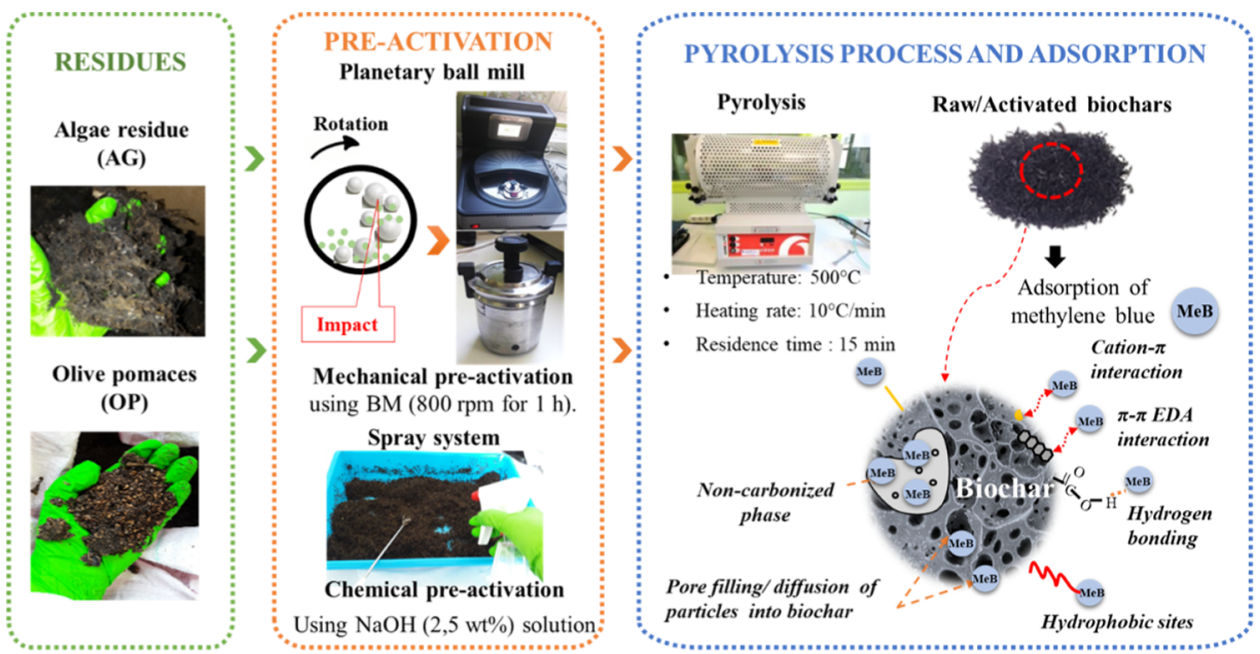

Figure 1. Overall preparation process of activated biochar production for methylene blue (MeB) adsorption.

of BCs. ${ }^{16,17}$ For instance, it has been reported that $\mathrm{NaOH}$ activated $\mathrm{BC}$ produced from hickory wood improved the adsorption capacity to $53.6 \mathrm{mg} / \mathrm{g}$ of $\mathrm{Pb}^{2+}$ compared to $11.2 \mathrm{mg} /$ $\mathrm{g}$ of $\mathrm{Pb}^{2+}$ for unactivated $\mathrm{BC} .{ }^{16}$ Similarly, it was reported that potassium hydroxide activation increased the surface area from 14.4 to $49.1 \mathrm{~m}^{2} / \mathrm{g}$ and the oxygen-containing functional groups of municipal solid waste-derived BC. ${ }^{18}$ Moreover, it was reported that the incorporation of humate sodium in biochar production (from the ground peanut shells (PS) and white clover (WC) residues, produced at $600{ }^{\circ} \mathrm{C}$ ) could increase the adsorption capacity of methylene blue $(\mathrm{MeB})$ onto the biochars from 10.79 to 16.21 and 8.62 to $11.03 \mathrm{mg} / \mathrm{g}$ for peanut shell and white clover residue biochars, respectively. ${ }^{3}$ However, alkaline activation has also demonstrated negative results. Sun et al. reported that potassium hydroxide decreased the surface area of wheat straw BC from 4.4 to $0.69 \mathrm{~m}^{2} / \mathrm{g}$, ${ }^{19}$ and it seems that the effect of alkaline activation on physicochemical changes and BC adsorption efficiency depends highly on the nature of the raw material. ${ }^{12}$ Mechanical activation is another promising strategy that could greatly improve the adsorption capacity of $\mathrm{BC} .^{14,20}$ Indeed, Wang et al. found that the ball milling activation increased the surface area of bamboo BC by 16 times (from 18.2 $\mathrm{m}^{2} / \mathrm{g}$ for the raw BC to $289.6 \mathrm{~m}^{2} / \mathrm{g}$ for the activated $\left.\mathrm{BC}\right){ }^{21}$ Currently, an important aspect to take into account is related to the environmental impact of chemical, mechanical, and physicochemical pretreatments, caused by high energy consumption, and the use of high quantity of water and chemicals that generate large amounts of waste streams. For these reasons, dry chemical and mechanical activations could be a promising alternative for biochar activation. Dry alkaline activation and ball milling activation are effective in improving the surface area and surface functional groups of BCs, which enhanced their adsorption capacity toward organic and inorganic contaminants.

In this work, we investigated the coupling of dry $\mathrm{NaOH}$ and ball milling (Figure 1) for BC activation produced from two industrial biomass residues (algae residue: $\mathrm{AG}$; olive pomace: OP) using pyrolysis (i.e., $500{ }^{\circ} \mathrm{C}, 10{ }^{\circ} \mathrm{C} / \mathrm{min}$, and $15 \mathrm{~min}$ ). Indeed, different activated $\mathrm{BCs}$ were characterized and their performances were evaluated using methylene blue (MeB) adsorption.

In this study, olive pomace (OP) and red macroalgae residue (AG) after agar-agar extraction were selected as a raw material for biochar production because of their abundance in Morocco.
Moroccan marine area represents $3500 \mathrm{~km}$ of coastline, ${ }^{22}$ and Gelidium sesquipedale red macroalgae represent $90 \%$ of the harvest of the marine macroalgae treated locally and generated an important quantity of macroalgae residue estimated to 870 tons/year. ${ }^{23,24}$ However, OP was chosen due to the high production of olive oil in Morocco. Indeed, according to the U.S. Department of Agriculture, Morocco was ranked third place as olive oil producing country in 2019 with 140000 metric tons of olive oil after Turkey and Tunisia at second and first places, respectively.

This study represents a continuous study of Tayibi et al. ${ }^{25}$ with an objective to produce activated biochar using a one-pot activation/pyrolysis method. The originality of this new process developed in this study is to use one-pot pyrolysis for activation and biochar production, using a spray system (Figure 1) and using low water content, without any washing, rinsing, and separation, and without effluent generation. This reduces activation steps, energy consumption, and the cost of the process.

The main objectives of this study are as follows:

- To investigate the effect of activation/pyrolysis on the physicochemical properties of activated BCs compared to raw BCs.

- To determine the efficiency of activated BCs as adsorbents of methylene blue (MeB).

- To study the effect of adsorption parameters, i.e., BC dose, $\mathrm{pH}$ of initial solution, $\mathrm{MeB}$ concentration, temperature, and contact time, on the performances of the activated BCs.

- To determine the isotherm and kinetic adsorption process of $\mathrm{MeB}$ onto all produced BCs to fit the experimental data.

- To investigate the thermodynamic study and determine the thermodynamic parameters of the adsorption process.

\section{RESULTS AND DISCUSSION}

Chemical and Biochemical Compositions of AG and OP Biomasses. Table 1 summarizes the results of ultimate, proximate, and fiber analyses of macroalgal residue (AG) and olive pomace (OP). AG has a low carbon content compared to OP (40.4 versus 50.9 wt \%). AG also has 1.1 and 2.4 wt \% lower hydrogen and oxygen contents, respectively, than OP. However, AG's nitrogen and sulfur contents were higher by 4.2 and $0.8 \mathrm{wt}$ $\%$, respectively, compared to OP biomass. The proximate 
Table 1. Proximate, Ultimate, and Fiber Analyses of Algae Residue (AG) and Olive Pomace (OP) Used in This Study and Their Equivalents Reported in the Literature

\begin{tabular}{|c|c|c|c|c|}
\hline parameter & AG & $\mathrm{OP}$ & $\begin{array}{l}\text { Gracilaria } \\
\text { gracilis }^{27}\end{array}$ & $\begin{array}{c}\text { olive } \\
\text { pomace }^{28}\end{array}$ \\
\hline \multicolumn{5}{|c|}{ Ultimate Analysis } \\
\hline $\mathrm{C}($ wt $\%)$ & $40.4 \pm 0.1$ & $50.9 \pm 0.2$ & 31.7 & 49.2 \\
\hline $\mathrm{H}($ wt \%) & $6.0 \pm 0.2$ & $7.1 \pm 0.2$ & 5.2 & 6.8 \\
\hline N (wt \%) & $5.1 \pm 0.1$ & $0.9 \pm 0.1$ & 4.0 & 2 \\
\hline S (wt \%) & $0.9 \pm 0.0$ & $0.1 \pm 0.0$ & 1.6 & 0 \\
\hline $\mathrm{O}^{a}(\mathrm{wt} \%)$ & $38.5 \pm 0.1$ & $35.8 \pm 0.3$ & 37.8 & 45.8 \\
\hline $\mathrm{H} / \mathrm{C}$ & 0.1 & 0.1 & & \\
\hline $\mathrm{O} / \mathrm{C}$ & 1 & 0.7 & & \\
\hline \multicolumn{5}{|c|}{ Fiber and Protein Composition } \\
\hline cellulose (wt \%) & $17.4 \pm 5.1$ & $6.8 \pm 0.4$ & & 34 \\
\hline $\begin{array}{l}\text { hemicelluloses } \\
\text { (wt \%) }\end{array}$ & $4.3 \pm 2.8$ & $10.3 \pm 0.0$ & & 15 \\
\hline lignin (wt \%) & $17.0 \pm 4.7$ & $36.2 \pm 2.2$ & & 20 \\
\hline proteins $^{b}$ (wt \%) & $31.9 \pm 0.5$ & $5.8 \pm 0.7$ & 25 & 12.5 \\
\hline \multicolumn{5}{|c|}{ Proximate Analysis } \\
\hline moisture (wt \%) & $5.4 \pm 0.3$ & $2.0 \pm 0.1$ & 9.13 & 5.7 \\
\hline $\begin{array}{l}\text { volatile matter } \\
\quad(\text { wt } \%)\end{array}$ & $65.8 \pm 2.1$ & $75.7 \pm 1.6$ & & 80.5 \\
\hline $\begin{array}{l}\text { fixed carbon } \\
\quad(\text { wt \%) }\end{array}$ & $18.7 \pm 0.9$ & $18.2 \pm 1.4$ & & 19.5 \\
\hline ash (wt \%) & $9.1 \pm 0.1$ & $5.2 \pm 0.1$ & 20.0 & 4.5 \\
\hline
\end{tabular}

analysis revealed that OP has high volatile matter (75.7 wt \%) and low ash content (5.2 wt \%) compared to AG, whereas fixed carbon was almost similar for both residues. Such values are in agreement with previous studies as listed in Table $1 .^{26-28}$ The hemicellulose and lignin contents of OP were 6 and 19.2 wt \% higher than those of AG, respectively, whereas cellulose content was 10.6 wt \% lower.

Yields and Chemical Composition of Produced Biochars. The yields of produced raw and activated BCs are presented in Figure 2. The yields of raw and activated BCs produced from AG were higher than those produced from $O P$ and ranged from $25.5 \mathrm{wt} \%$ for BCOP to $34.8 \mathrm{wt} \%$ for BCAG$\mathrm{NaOH}$. Interestingly, preactivation of $\mathrm{AG}$ and $\mathrm{OP}$ biomasses (chemical or mechanical) did not influence the yield of $\mathrm{BC}$ compared to raw materials. The AG-BC yields are in the same range of $\mathrm{BC}$ produced from palm shell at $600{ }^{\circ} \mathrm{C}(31.8 \mathrm{wt} \%),{ }^{28}$ whereas the OP-BC yields are close to the $\mathrm{BC}$ produced from sugarcane bagasse $(27.7 \mathrm{wt} \%){ }^{28}$ It was reported that the inorganic matter, especially alkali metals (i.e., $\mathrm{K}, \mathrm{Na}$, etc.) that represent the ash content, can play a crucial role in shifting the balance in favor of heat release because of its catalytic effect, which simultaneously reduces the energy requirements for the volatilization of biochemical compounds and promotes the exothermic secondary char formation. ${ }^{29}$ Therefore, it could be suggested that the high ash content in AG (9.1 wt \%) has promoted $\mathrm{BC}$-forming reactions in account of decomposition reactions. Ultimate and proximate analyses of all produced $\mathrm{BCs}$ are presented in Table 2. Here, BC carbon content varied from 50.7 wt \% for BCAG-NaOH and BCAG-BM to 72.1 wt \% for $\mathrm{BCOP}$ and represents the most abundant element. ${ }^{30}$

The chemical and mechanical activations have led to a slight decrease of carbon content in BCOP-NaOH and BCOP-BM compared to the raw materials. For AG-BC, both activations led to a decrease of $10.4 \mathrm{wt} \%$ of $\mathrm{C}$ in BCAG-NaOH and BCAG-BM.

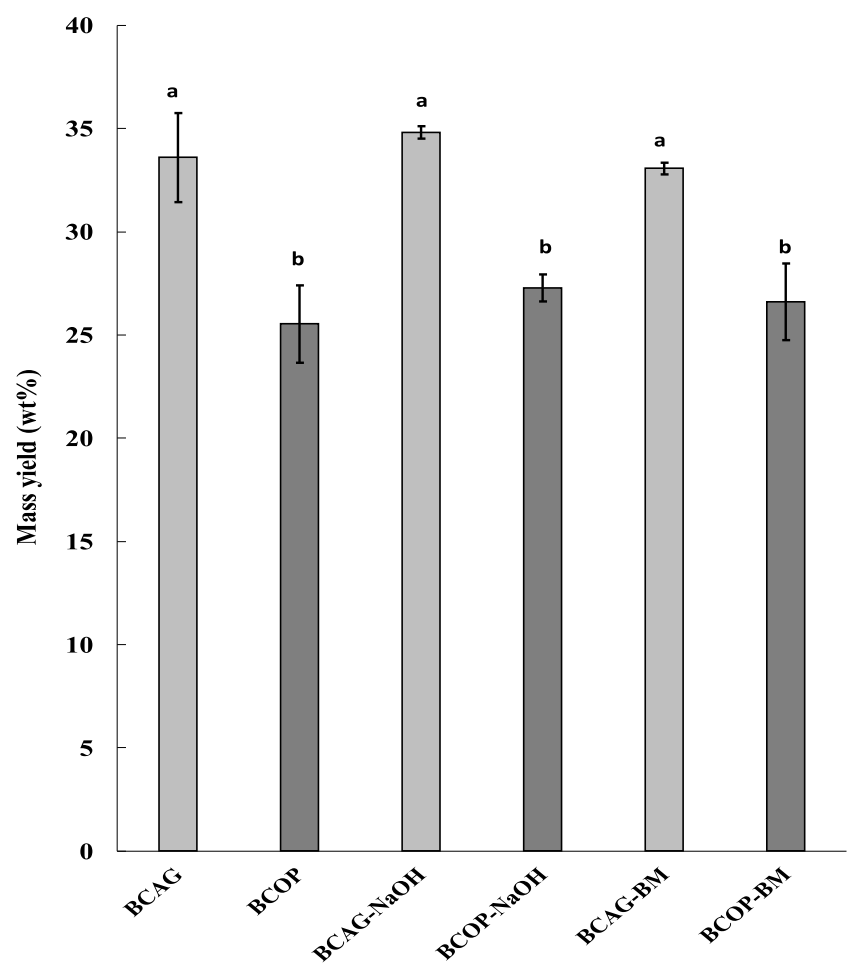

Figure 2. Mass yield percentages of different biochars (raw and activated) produced from AG and OP residues. Different lowercase letters indicate significant differences (analysis of variance, ANOVA test, $p \leq 0.05$ ) between biochars.

Finally, the hydrogen content ranged from $2.4 \mathrm{wt} \%$ for BCAG$\mathrm{BM}$ to $4 \mathrm{wt} \%$ for $\mathrm{BCOP}$, while the nitrogen content ranged from 6.9 wt $\%$ for BCAG to 4.8 wt \% for BCOP. After carbon, oxygen was the most affected element. Compared to BCAG, the oxygen content was increased from 14.4 to 21.3 and $21.7 \mathrm{wt} \%$ in BCAG$\mathrm{NaOH}$ and BCAG-BM, respectively. However, for BCOP, it increased from 12.3 to 14.4 and 14.6 wt $\%$ for $\mathrm{BCOP}-\mathrm{NaOH}$ and $\mathrm{BCOP}-\mathrm{BM}$, respectively. An interesting observation was also noticed in terms of the molar ratio of oxygen and carbon that describes the surface hydrophobicity of BCs. ${ }^{31}$ For BCAG, the $\mathrm{O} / \mathrm{C}$ ratio tends to first decrease from 1.0 for $A G$ to 0.24 for BCAG due to the decarboxylation reactions during pyrolysis. ${ }^{32}$ Furthermore, both activation methods tend to enhance the polarity of activated BCs. The $\mathrm{O} / \mathrm{C}$ ratio increased from 0.24 for BCAG to 0.42 and 0.43 for BCAG-NaOH and BCAG-BM, respectively. However, the $\mathrm{O} / \mathrm{C}$ ratio for $\mathrm{BCOP}$ tends to increase from 0.17 to 0.20 and 0.21 for $\mathrm{BCOP}-\mathrm{NaOH}$ and BCOP-BM, respectively.

These results indicated that the polarity of BCs depends on the nature of the biomass used and pyrolysis conditions, but both chemical and mechanical activations were conducted to increase the polar group content of BCs (i.e., hydroxyl, carboxylate, and carbonyl groups). These oxygenated functional groups can contribute to high cationic exchange capacity ${ }^{33}$ and high surface charge ( $\zeta$-potential) of activated BCs. ${ }^{34}$ In addition, the molar ratio of hydrogen and carbon $(\mathrm{H} / \mathrm{C})$ indicated the degree of carbonization. ${ }^{33} \mathrm{AG}$ and $\mathrm{OP}$ showed a change in the $\mathrm{H} / \mathrm{C}$ ratio after pyrolysis; it was a decrease from 0.1 for both $\mathrm{AG}$ and OP to 0.04 and 0.06 for BCAG and BCOP, respectively. During pyrolysis reaction, the biomass lost hydrogen due to the volatilization of hydrocarbon species and conducted to an increase in the carbon content and an increase in the aromatic 
Table 2. Chemical Composition and Physicochemical Properties of Different Biochars (Activated or Not) Produced from Algae Residue and Olive Pomace ${ }^{b}$

\begin{tabular}{|c|c|c|c|c|c|c|c|}
\hline \multirow[b]{2}{*}{ analysis and characterization } & \multirow[b]{2}{*}{ parameters } & \multicolumn{3}{|c|}{ from algae residue } & \multicolumn{3}{|c|}{ from olive pomace } \\
\hline & & BCAG & BCAG-NaOH & BCAG-BM & BCOP & BCOP-NaOH & BCOP-BM \\
\hline \multirow[t]{7}{*}{ ultimate analysis } & $\mathrm{C} \%$ & $61.1 \pm 0.1$ & $50.7 \pm 0.3$ & $50.7 \pm 0.1$ & $72.1 \pm 0.1$ & $71.5 \pm 0.1$ & $70.4 \pm 0.3$ \\
\hline & $\mathrm{H} \%$ & $2.6 \pm 0.0$ & $2.5 \pm 0.1$ & $2.4 \pm 0.0$ & $4.0 \pm 0.1$ & $2.8 \pm 0.1$ & $2.7 \pm 0.0$ \\
\hline & $\mathrm{N} \%$ & $6.9 \pm 0.1$ & $5.7 \pm 0.3$ & $5.8 \pm 0.0$ & $1.0 \pm 0.2$ & $0.4 \pm 0.0$ & $2.0 \pm 0.2$ \\
\hline & $S \%$ & $1.5 \pm 0.2$ & $1.5 \pm 0.1$ & $1.3 \pm 0.1$ & $0.0 \pm 0.0$ & $0.0 \pm 0.0$ & $0.1 \pm 0.0$ \\
\hline & $\mathrm{O} \%^{a}$ & $14.4 \pm 0.1$ & $21.3 \pm 0.5$ & $21.7 \pm 0.2$ & $12.3 \pm 0.1$ & $14.4 \pm 0.2$ & $14.6 \pm 0.2$ \\
\hline & $\mathrm{H} / \mathrm{C}$ & $0.04 \pm 0.0$ & $0.05 \pm 0.0$ & $0.05 \pm 0.0$ & $0.06 \pm 0.0$ & $0.04 \pm 0.0$ & $0.04 \pm 0.0$ \\
\hline & $\mathrm{O} / \mathrm{C}$ & $0.24 \pm 0.0$ & $0.42 \pm 0.01$ & $0.43 \pm 0.0$ & $0.17 \pm 0.0$ & $0.20 \pm 0.0$ & $0.21 \pm 0.0$ \\
\hline \multirow[t]{4}{*}{ proximate analysis } & moisture wt \% & $6.5 \pm 0.3$ & $6.4 \pm 0.3$ & $6.7 \pm 0.1$ & $4.8 \pm 0.6$ & $6.0 \pm 0.6$ & $5.6 \pm 0.6$ \\
\hline & volatile matter wt $\%$ & $48.1 \pm 0.3$ & $36.8 \pm 1.3$ & $33.9 \pm 2.8$ & $26.5 \pm 0.0$ & $29.7 \pm 3.4$ & $21.1 \pm 4.8$ \\
\hline & fixed carbon wt \% & $35.6 \pm 5.2$ & $38.6 \pm 2.6$ & $40.3 \pm 2.2$ & $66.5 \pm 0.5$ & $53.5 \pm 4.0$ & $63.1 \pm 5.6$ \\
\hline & ash wt \% & $9.8 \pm 4.6$ & $18.3 \pm 1.2$ & $18.3 \pm 4.0$ & $7.6 \pm 0.5$ & $10.9 \pm 1.5$ & $10.2 \pm 0.2$ \\
\hline \multirow[t]{3}{*}{ physicochemical and surface properties } & $\mathrm{pH}$ & $9.6 \pm 0.0^{\mathrm{a}}$ & $11.0 \pm 0.0^{\mathrm{a}}$ & $11.2 \pm 0.0^{\mathrm{a}}$ & $11.2 \pm 0.0^{\mathrm{a}}$ & $12.9 \pm 0.3^{\mathrm{a}}$ & $12.0 \pm 0.1^{\mathrm{a}}$ \\
\hline & $\zeta$-potential $(\mathrm{mV})$ & $22.8 \pm 1.2^{\mathrm{a}}$ & $34.2 \pm 2.6^{\mathrm{b}}$ & $38.9 \pm 0.4^{b c}$ & $39.8 \pm 1.2^{\mathrm{c}}$ & $26.7 \pm 0.4^{\mathrm{a}}$ & $59.7 \pm 0.4^{\mathrm{d}}$ \\
\hline & $S_{\mathrm{BET}}\left(\mathrm{m}^{2} / \mathrm{g}\right)$ & 1.1 & 2.9 & 3.3 & 0.9 & 2.4 & 3.8 \\
\hline
\end{tabular}

structure in BCs. ${ }^{28}$ For both biomasses (AG and OP), H/C ratios of activated $\mathrm{BCs}$ were the same and did not show a high difference compared to raw BCs; however, the $\mathrm{H} / \mathrm{C}$ ratio of activated $\mathrm{BCAG}$ tended to increase by 0.01 compared to raw BCAG, whereas that of activated BCOP tended to decrease by 0.02 compared to BCOP. Moisture, volatile matter, fixed carbon, and ash determined from thermogravimetric analyzer (TGA) of all produced biochars are given in Table 2 . The volatile matter content varied from $48.1 \mathrm{wt} \%$ for BCAG to $21.1 \mathrm{wt} \%$ for BCOP-BM, while the fixed carbon content varied from $66.5 \mathrm{wt}$ $\%$ for BCOP to $35.6 \mathrm{wt} \%$ for BCAG. Ash content of BC mainly depends on feedstock, as previously mentioned, and the ash content of AG biomass was higher than that of OP. Therefore, all biochars from AG exhibited high ash content compared to biochars from OP (Table 2); in addition, chemical and mechanical activations led to the same increase in ash content for BCAG- and BCOP-activated biochars.

Physicochemical Properties of Biochars and Activated Biochars. Fourier-transform infrared (FTIR) spectroscopy analysis was performed to identify the different functional groups induced by different activation methods. Figure S1 (the Supporting Information) represents the FTIR spectra of AG and BCAG (Figure S1a) and the FTIR spectra of OP residue and BCOP (Figure S1b). OP and AG FTIR spectra showed a large peak between 3200 and $3500 \mathrm{~cm}^{-1}$ corresponding to the stretching vibration of $-\mathrm{O}-\mathrm{H}$ groups, indicating the presence of polysaccharides and proteins. ${ }^{23}$ The symmetric and asymmetric stretching vibrations of $-\mathrm{C}-\mathrm{H}$ groups were also detected as two peaks between 2700 and $3000 \mathrm{~cm}^{-1}$ for both samples; however, the peak intensities were higher in OP than in AG, indicating the presence of aliphatic groups such as methyl and methylene groups. ${ }^{36}$ These peaks were completely absent in all produced $\mathrm{BCAG}$ and $\mathrm{BCOP}$, indicating that $-\mathrm{O}-\mathrm{H}$ and $-\mathrm{CH}_{3}$ were removed or transformed with pre-activation/pyrolysis process ${ }^{7}$ except for BCOP-NaOH and BCOP-BM. These two activated BCs showed the presence of hydroxyl groups (3457 versus 3607 $\mathrm{cm}^{-1}$, respectively), which could be assigned to the hydroxyl groups provided by $\mathrm{NaOH}$ catalysis for $\mathrm{BCOP}-\mathrm{NaOH}$. However, for BCOP-BM, the $\mathrm{OH}$ groups could be a result of the $\mathrm{BM}$ effect in the $\mathrm{OP}$ structure, which may introduce numerous oxygen-containing functional groups such as carboxyl and hydroxyl groups on the BCOP-BM surface. ${ }^{14}$ A peak at 1716 $\mathrm{cm}^{-1}$, corresponding to $\mathrm{C}=\mathrm{O}$ carboxyl groups, was only present in OP (Figure S1b); this peak completely disappeared in BCs after pyrolysis. $\mathrm{C}=\mathrm{O}$ carbonyl groups were detected in both samples around $1640 \mathrm{~cm}^{-1}$. This peak disappeared in all BCAG and BCOP-BM, whereas it was shifted from $1642 \mathrm{~cm}^{-1}$ to a lower energy of $1608 \mathrm{~cm}^{-1}$ in BCOP and to a higher energy of $1681 \mathrm{~cm}^{-1}$ in BCOP-BM. This shifting was probably due to the carbonization $^{7}$ and activation processes. The presence of aromatic $\mathrm{C}=\mathrm{C}$ rings was proven by the presence of peaks around $1560-1590 \mathrm{~cm}^{-1}$, which assigned the vibrations in condensed aromatic carbon skeletons, ${ }^{36}$ and they occurred in BCAG-NaOH, BCAG-BM, and BCOP-BM. This peak was obviously bigger and sharper in BCOP-BM spectrum, indicating that mechanical modification/pyrolysis of OP leads to a $\mathrm{BC}$ with aromatic graphene structure likely contributing to $\mathrm{MeB}$ adsorption through $\pi-\pi$ electron donor-acceptor (EDA) interactions. ${ }^{11}$ Some peaks were observed at $700-950 \mathrm{~cm}^{-1}$, assigned for out-of-plan deformation mode of $\mathrm{C}-\mathrm{H}$ in various aromatic rings and alkene. ${ }^{37}$ BCOP-BM showed the most intense peak at $700 \mathrm{~cm}^{-1}$.

All produced $\mathrm{BCs}$ showed an alkaline $\mathrm{pH}$ (Table 2) ranging from 9.6 for BCAG to 12.9 for $\mathrm{BCOP}-\mathrm{NaOH}$, and it was evidenced that activation process led to an increase of $\mathrm{pH}$ compared to raw BCs. The alkalinity of produced BCs is generally related to the organic functional groups, carbonates, and inorganic alkalies. ${ }^{38}$ The $\zeta$-potential values of produced BCs are presented in Table 2. In this study, the surface charge of produced $\mathrm{BCs}$ ranged from $-22.8 \mathrm{mV}$ for $\mathrm{BCAG}$ to $-59.7 \mathrm{mV}$ for BCOP-BM, indicating that the surfaces of all BCs were negatively charged. ${ }^{39}$ BCOP-BM carried more negative charges than $\mathrm{BCOP}-\mathrm{NaOH}$; in addition, the latter showed a decrease of $-13.1 \mathrm{mV}$ compared to BCOP. Compared to the $\zeta$-potential of BCAG, it can be seen that alkaline activation increased the surface charge from -22.8 to $-34.2 \mathrm{mV}$ (in terms of absolute value); on the other hand, BM activation has led to an increase of $\zeta$-potential by $-4.7 \mathrm{mV}$ compared to BCAG-NaOH.

Effects of Operating Conditions on MeB Adsorption. Effects of Adsorbent Dose and the Initial Solution $\mathrm{pH}$. Biochar (BC) dose is a significant factor influencing the $\mathrm{MeB}$ adsorption. Generally, the removal efficiency of $\mathrm{MeB}$ increased with increasing $\mathrm{BC}$ dose at a constant $\mathrm{MeB}$ concentration. ${ }^{40}$ Figure S2 presents the results of the adsorption tests (the Supporting 

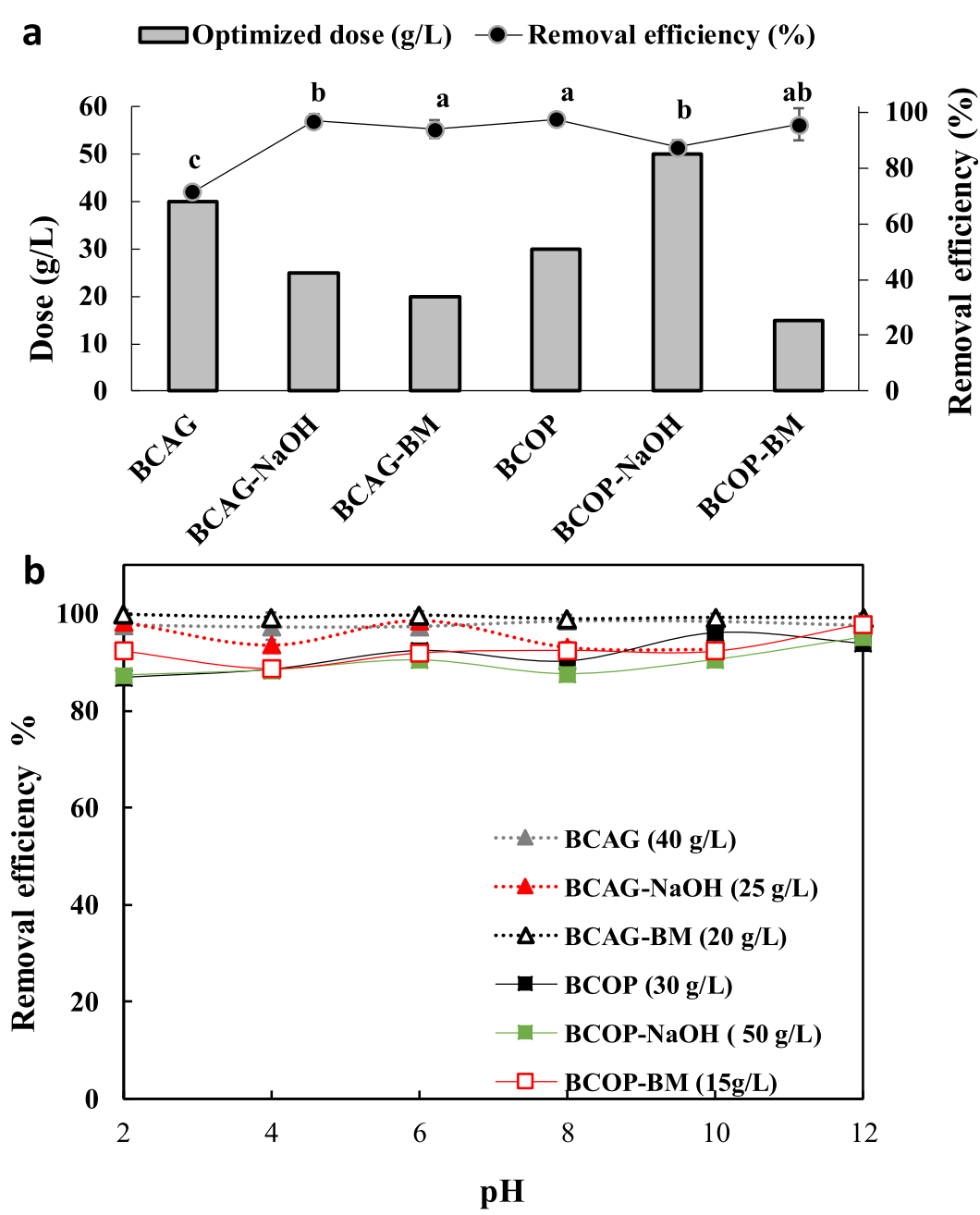

Figure 3. (a) Appropriate biochar doses and removal efficiencies of different produced biochars concluded from the optimized dose experiment shown in Figure S2 (the Supporting Information) (different lowercase letters indicate significant differences $(p \leq 0.05)$ between the removal efficiency of different biochars) and (b) effects of initial $\mathrm{pH}$ on the adsorption of $\mathrm{MeB}$ onto different biochars (using optimized dose of each biochar).

Information) for the purpose of determining the optimized adsorbent concentration (varying from 10 to $55 \mathrm{~g} \mathrm{BC/L}$ with 50 $\mathrm{mg} / \mathrm{L}$ of $\mathrm{MeB}$ for $360 \mathrm{~min}$ ). The optimized doses of different BCs are presented in Figure 3a. The results show that $\mathrm{NaOH}$ and $\mathrm{BM}$ activation of $\mathrm{BC}$ influenced the removal efficiency of $\mathrm{MeB}$ (Figure 3a). The removal efficiency of $\mathrm{MeB}$ increased for activated $\mathrm{BC}$ produced from AG compared to the raw one; however, the dose quantity decreased, which indicates the increase in available sorption surfaces and adsorption sites due to the positive advantages of activation processes. ${ }^{41}$ BCAG showed $71.54 \%$ of removal efficiency using $40 \mathrm{~g} / \mathrm{L}$, whereas BCAG-NaOH and BCAG-BM attained a removal efficiency of 96.97 and $93.99 \%$ using only 25 and $20 \mathrm{~g} / \mathrm{L}$, respectively. For the $\mathrm{BC}$ produced from OP, BCOP-BM showed the most promising results, using only $15 \mathrm{~g} / \mathrm{L}$ conducted to $95.7 \%$ of $\mathrm{MeB}$ removal, while BCOP and BCOP-NaOH needed 30 and $50 \mathrm{~g} / \mathrm{L}$ to reach 97.6 and $87.6 \%$ of $\mathrm{MeB}$ removal, respectively. By maintaining the optimized dose of different produced BCs, the effects of initial $\mathrm{pH}$ values $(2-12)$ on $\mathrm{MeB}$ adsorption have been investigated and the results are presented in Figure $3 \mathrm{~b}$. The $\mathrm{pH}$ variation in the initial $\mathrm{MeB}$ solution did not exhibit a significant effect on the efficiency of $\mathrm{MeB}$ removal for all BCs (raw and activated). These results could be explained by the high alkalinity ( $\mathrm{pH}$ varied from 10 to $\sim 13$ as shown in Table 2 ) of different produced $\mathrm{BCs}$. The $\mathrm{pH}$ of the $\mathrm{BC}$ and $\mathrm{MeB}$ solution mixture indicates the $\mathrm{pH}$ values ranging between 9 and 12, and the results confirmed that the highest $\mathrm{MeB}$ removal was found in this range (Figure $3 \mathrm{~b}$ ). It was reported that alkaline condition favors the removal of $\mathrm{MeB}$, indicating that high $\mathrm{pH}$ excited electrostatic interaction between $\mathrm{MeB}$ and $\mathrm{BC} .^{40}$ Therefore, the $\mathrm{pH}$ of $\mathrm{MeB}$ solution is 7.4 , and it was not adjusted in the subsequent kinetic and isotherm experiments.

Effect of Contact Time. The effect of contact time with the optimized concentration of BC is shown in Figure 4. Adsorption is rapid during the initial period of contact time $(0-60 \mathrm{~min})$ and then becomes slow and stagnated with further increase of contact time, similar to the results of Sun et al. These findings can be explained by the fact that most vacant surface sites are available for adsorption during the initial period and the remaining ones are hard to be utilized due to repulsive forces between the $\mathrm{MeB}$ molecules on $\mathrm{BC}$ surface. ${ }^{42}$ With an optimized dose of $15 \mathrm{~g} / \mathrm{L}, \mathrm{BCOP}-\mathrm{BM}$ depicted the highest removal efficiency of $87.7 \%$ after only $60 \mathrm{~min}$, whereas BCOP and BCOP-NaOH needed 30 and $50 \mathrm{~g} / \mathrm{L}$ to reach 71.3 and $78.3 \%$ of removal efficiencies, respectively, for the same period. BCAG$\mathrm{NaOH}$ and BCAG-BM showed almost the same trend for $\mathrm{MeB}$ adsorption; they attained 77.9 and $77.7 \%$ of $\mathrm{MeB}$ removal using an optimized concentration of 25 and $20 \mathrm{~g} / \mathrm{L}$, respectively, compared to BCAG, which achieved only $68.3 \%$ of $\mathrm{MeB}$ 


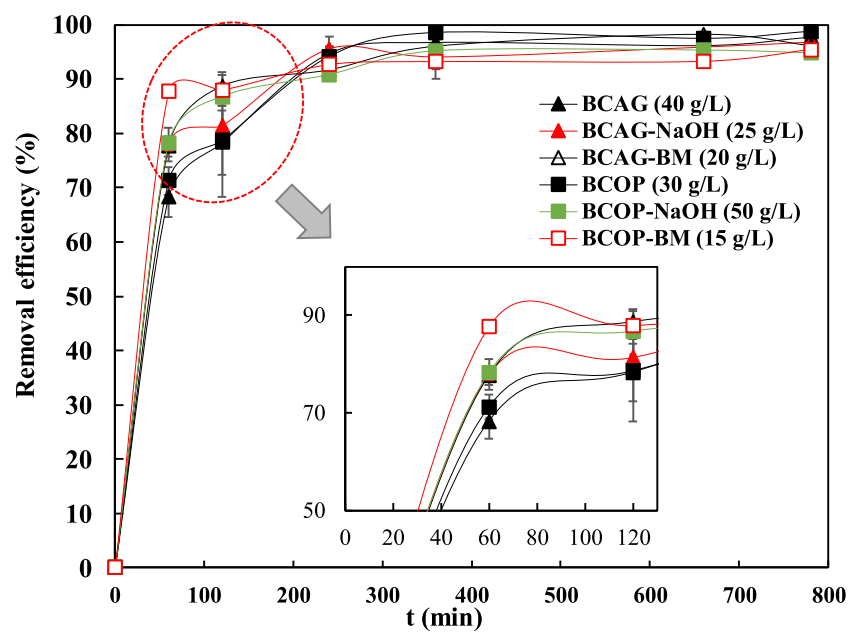

Figure 4. Effect of contact time on the adsorption of $\mathrm{MeB}$ onto different biochars (using optimized dose of each adsorbent).

removal using almost double the amount $(40 \mathrm{~g} / \mathrm{L})$ used for activated BC.

Adsorption Kinetics. The nonlinear kinetic models fitting the pseudo-first-order (PFO), pseudo-second-order (PSO), and intraparticle diffusion (ID) are illustrated in Figure S3 (the Supporting Information). The values of the kinetic adsorption parameters for various BCs have been determined and summarized in Table 3. Figure S3a,b presents the fitting plots of nonlinear PFO and PSO models, and according to the obtained $R^{2}$ values (Table 3 ), the kinetic data of all biochars produced from AG fitted well with the PFO model, while the kinetic data of OP biochars fitted well with PSO, except for $\mathrm{BCOP}-\mathrm{NaOH}$. Furthermore, the $q_{\mathrm{cal}}$ values were remarkably close to the experimental values $q_{\mathrm{e} \text { exp }}$ and matched well with the results of $R^{2}$ (Table 3). The normalized standard deviation $\Delta q$ values (Table 3 ) determined from PFO and PSO data were in accordance with the results of $R^{2}$; they ranged from 0.02 to $2.24 \%$ for PFO data versus $1.62-4.73 \%$ for PSO data for AG biochars (raw and activated) and $\mathrm{BCOP}-\mathrm{NaOH}$. However, the $\Delta q$ values were 3.03 and $0.26 \%$ based on PSO data of BCOP and BCOP-BM, respectively, compared to 4.21 and $1.99 \%$ based on PFO data, respectively.

These results are consistent with previously reported studies in the literature. ${ }^{43,44}$ To analyze in depth the adsorption kinetics data, the intraparticle diffusion model was applied (Figure S3c) according to $\mathrm{Zhu}$ et al. and the fitted parameters are summarized in Table 3. As shown in the Figure S3c, the plots of the MeB adsorption capacities of $\mathrm{BC}$ versus $t^{1 / 2}$ showed a linear relationship. The first linear part of the curve represents the surface adsorption, whereas the second linear portion shows the slow diffusion of $\mathrm{MeB}$ onto the surface to the inner holes. ${ }^{45}$ However, the lines of the plots did not pass through the origin $C$ $\neq 0$, indicating that the rate-controlling step did not only involve intraparticle diffusion but also boundary layer diffusion to some degree. $^{46}$

Adsorption Isotherm. The adsorption isotherm plots for various BCs are shown in Figure 5. The fitting parameters of the adsorption isothermal models, the correlation coefficients of the experimental data, and the Marquardt's percentage standard deviation (MPSD) error function values are presented in Table 4. The results showed that the correlation coefficients indicate that the Langmuir model fitted better than the Freundlich model for different BCs. This means that the active sites of BC were homogeneously distributed and have the same adsorption energy, and the $\mathrm{MeB}$ adsorption on $\mathrm{BC}$ was likely to be a monolayer. ${ }^{6}$ Even though the correlation coefficient suggested the Langmuir model, the MPSD error function values from Langmuir data and Freundlich were similar, except for BCOP$\mathrm{BM}$ that showed a higher value of 50 from Langmuir data compared to 1.7 from Freundlich data. The highest adsorption capacities were obtained for BCOP-BM, followed by BCAG$\mathrm{NaOH}$ and BCAG-BM with $31.81,13.09$, and $9.12 \mathrm{mg} / \mathrm{g}$, respectively. On the contrary, $\mathrm{BCOP}-\mathrm{NaOH}, \mathrm{BCOP}$, and BCAG showed lower adsorption capacities of 2.62, 2.97, and $4.06 \mathrm{mg} / \mathrm{g}$, respectively. A dimensionless separation factor $\left(R_{\mathrm{L}}\right)$ defined based on the Langmuir isotherm model was also determined. It was reported that $0<R_{\mathrm{L}}<1$ indicates favorable adsorption, $R_{\mathrm{L}}>1$ indicates unfavorable adsorption, $R_{\mathrm{L}}=0$ indicates irreversible adsorption, and $R_{\mathrm{L}}=1$ indicates linear adsorption. $^{39}$

In this study, Figure $5 \mathrm{c}$ shows that this factor was found to be varying from 0.077 to 0.400 for $\mathrm{BCAG}$ and $\mathrm{BCAG}-\mathrm{NaOH}, 0.059$ to 0.333 for BCAG-BM, 0.014 to 0.100 for BCOP, 0.010 to 0.074 for BCAG-NaOH, and 0.385 to 0.833 for BCOP-BM. These values were $<1$ for all produced BCs (raw and activated); furthermore, with the increase of initial MeB concentration, $R_{\mathrm{L}}$ decreased (Figure 5c), which suggested that the Langmuir isotherm was favorable for adsorption of $\mathrm{MeB}$ on the $\mathrm{BC}$ under the conditions used in this study. ${ }^{15}$ The comparison of ours results with the literature is reported in Table 5. Comparing the

Table 3. Kinetic Parameters of All Biochars Using PFO, PSO (Nonlinear), and ID Kinetic Models

\begin{tabular}{|c|c|c|c|c|c|c|c|}
\hline & \multirow[b]{2}{*}{ kinetic parameters } & \multicolumn{3}{|c|}{ algae residue biochars } & \multicolumn{3}{|c|}{ olive pomace biochars } \\
\hline & & BCAG & BCAG-NaOH & BCAG-BM & BCOP & BCOP-NaOH & BCOP-BM \\
\hline \multirow{4}{*}{$\mathrm{PFO}$} & $q_{\mathrm{e}, \exp }(\mathrm{mg} / \mathrm{g})$ & 1.223 & 1.987 & 2.490 & 1.646 & 0.955 & 3.265 \\
\hline & $q_{\mathrm{e}, \mathrm{cal}}(\mathrm{mg} / \mathrm{g})$ & 1.162 & 1.961 & 2.430 & 1.491 & 0.955 & 3.120 \\
\hline & $K_{1}(1 / \min )$ & 0.018 & 0.015 & 0.018 & 0.018 & 0.039 & 0.023 \\
\hline & $R^{2}$ & 0.78 & 0.94 & 0.89 & 0.58 & 0.98 & 0.80 \\
\hline \multirow{3}{*}{ PSO } & $\Delta q(\%)$ & 2.24 & 0.59 & 1.08 & 4.21 & 0.02 & 1.99 \\
\hline & $q_{\mathrm{e}, \mathrm{cal}}(\mathrm{mg} / \mathrm{g})$ & 1.286 & 2.152 & 2.580 & 1.757 & 1.056 & 3.246 \\
\hline & $K_{2}(g /(\operatorname{mg} \min ))$ & 0.025 & 0.015 & 0.016 & 0.018 & 0.025 & 0.028 \\
\hline \multirow{5}{*}{ ID } & $R^{2}$ & 0.77 & 0.63 & 0.84 & 0.70 & 0.53 & 0.97 \\
\hline & $\Delta q(\%)$ & 2.32 & 3.71 & 1.62 & 3.03 & 4.73 & 0.26 \\
\hline & $K_{\mathrm{d}}\left(\mathrm{mg} /\left(\mathrm{g} \min ^{1 / 2}\right)\right)$ & 0.012 & 0.022 & 0.024 & 0.022 & 0.004 & 0.014 \\
\hline & $C$ & 0.814 & 1.456 & 1.914 & 1.112 & 0.867 & 2.870 \\
\hline & $R^{2}$ & 0.732 & 0.796 & 0.722 & 0.765 & 0.655 & 0.828 \\
\hline
\end{tabular}



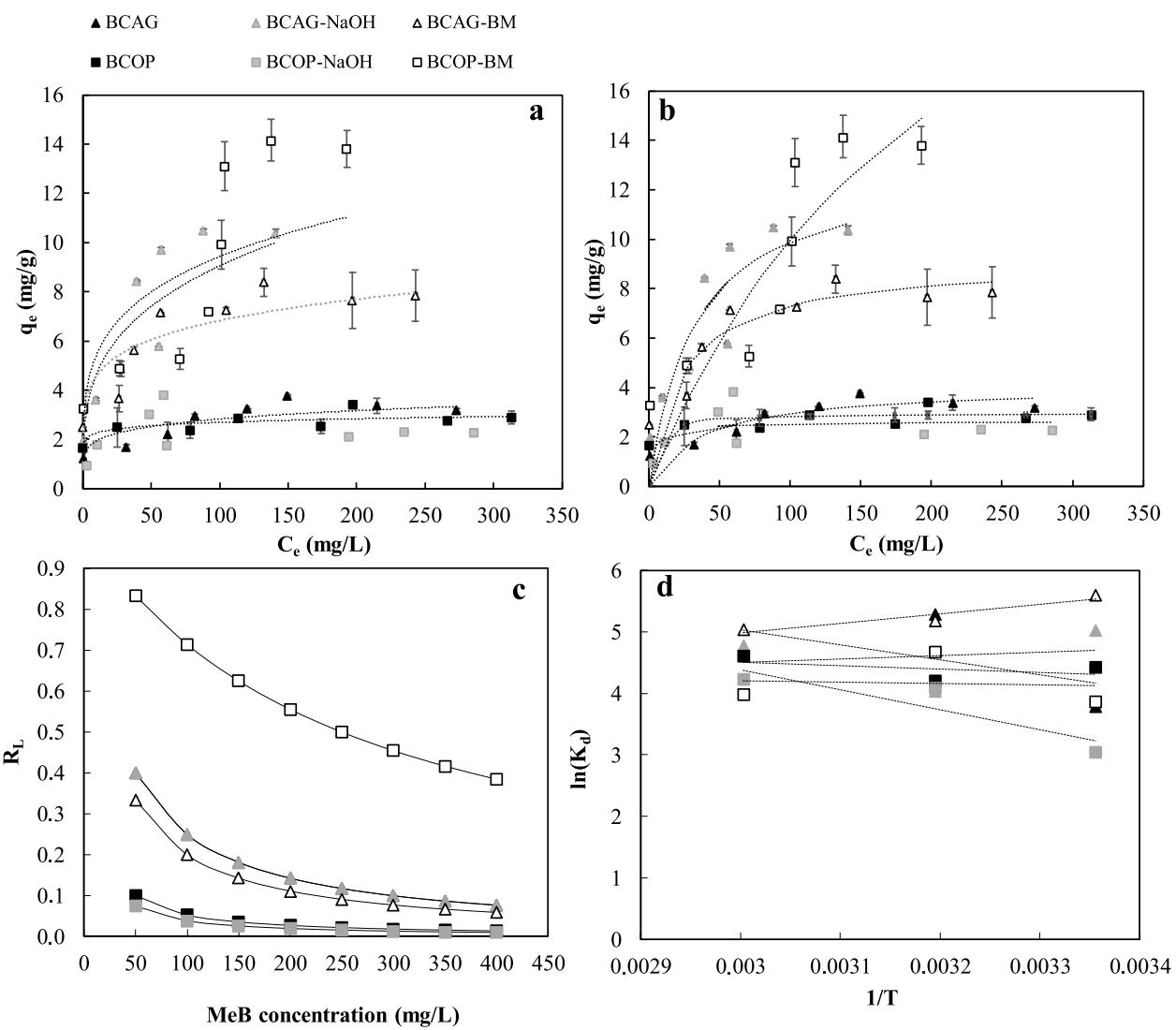

Figure 5. Adsorption isotherm model plots of $\mathrm{MeB}$ adsorption on all produced biochars: (a) nonlinear Langmuir adsorption model; (b) nonlinear Freundlich adsorption model, $(c)$ dimensionless separation factor at different initial MeB concentrations; and (d) plot of $\ln \left(K_{d}\right)$ against $1 / T$ for the adsorption of $\mathrm{MeB}$ onto all produced biochars.

Table 4. Adsorption Isotherm and Thermodynamic Parameters of MeB Adsorption for Various Biochars Investigated

\begin{tabular}{|c|c|c|c|c|c|c|c|c|c|c|c|c|c|}
\hline \multirow[b]{3}{*}{ adsorbent } & \multirow{2}{*}{\multicolumn{4}{|c|}{ Langmuir parameters }} & \multirow{2}{*}{\multicolumn{4}{|c|}{ Freundlich parameters }} & \multicolumn{5}{|c|}{ thermodynamic parameters } \\
\hline & & & & & & & & & \multirow[b]{2}{*}{$\begin{array}{c}\Delta H^{\circ} \\
(\mathrm{kJ} / \mathrm{mol})\end{array}$} & \multirow[b]{2}{*}{$\begin{array}{c}\Delta S^{\circ} \\
(\mathrm{J} /(\mathrm{K} \mathrm{mol}))\end{array}$} & \multicolumn{3}{|c|}{$\Delta G^{\circ}(\mathrm{kJ} / \mathrm{mol})$} \\
\hline & $\begin{array}{c}Q_{0} \\
(\mathrm{mg} / \mathrm{g})\end{array}$ & $\begin{array}{c}K_{\mathrm{L}} \\
(\mathrm{L} / \mathrm{mg})\end{array}$ & $R^{2}$ & MPSD & $\left(\mathrm{mg}^{1-b_{\mathrm{F}}} \mathrm{L}^{b_{\mathrm{F}}} \mathrm{g}^{-1}\right)$ & $b_{\mathrm{F}}$ & $R^{2}$ & MPSD & & & $T=298 \mathrm{~K}$ & $T=313 \mathrm{~K}$ & $T=333 \mathrm{~K}$ \\
\hline BCAG & 4.06 & 0.03 & 0.82 & 6.84 & 1.33 & 0.16 & 0.80 & 1.28 & 20.2 & 102.5 & -9.4 & -13.9 & -13.0 \\
\hline BCAG-NaOH & 13.09 & 0.03 & 0.87 & 10.79 & 2.40 & 0.29 & 0.86 & 12.33 & -4.6 & 23.6 & -12.4 & -10.5 & -13.2 \\
\hline BCAG-BM & 9.12 & 0.04 & 0.79 & 5.47 & 3.08 & 0.17 & 0.84 & 3.39 & -13.0 & 2.3 & -13.9 & -13.5 & -13.9 \\
\hline $\mathrm{BCOP}$ & 2.97 & 0.18 & 0.63 & 0.71 & 1.90 & 0.08 & 0.80 & 0.45 & 4.7 & 51.7 & -10.9 & -10.9 & -12.7 \\
\hline BCOP-NaOH & 2.62 & 0.25 & 0.64 & 6.65 & 1.11 & 0.16 & 0.38 & 11.26 & 27.3 & 118.4 & -7.5 & -10.6 & -13.7 \\
\hline BCOP-BM & 31.81 & 0.004 & 0.98 & 50.01 & 3.15 & 0.24 & 0.66 & 1.56 & 1.4 & 40.2 & -9.6 & -12.1 & -11.0 \\
\hline
\end{tabular}

raw produced $\mathrm{BC}$ prepared from eucalyptus and palm bark, ${ }^{47}$ BCAG and BCOP showed higher adsorption capacities of $\mathrm{MeB}$ (Table 5). BM-activated BC produced from sugarcane bagasse reported by Lyu et al. showed great results in $\mathrm{MeB}$ adsorption compared to $\mathrm{BC}$ produced in this study. It was reported that the adsorption capacity was $354 \mathrm{mg} / \mathrm{g}$, which was explained by the high $S_{\text {BET }}$ of $331 \mathrm{~m}^{2} / \mathrm{g} .{ }^{14}$ However, BCAG-NaOH and BCOP$\mathrm{BM}$ had better adsorption performances compared to carbon nanotube (CNT)-modified BC (1\%) reported by Inyang et al. ${ }^{13}$ Despite the large $S_{\mathrm{BET}}$ value of $390 \mathrm{~m}^{2} / \mathrm{g}$ versus $2.9 \mathrm{~m}^{2} / \mathrm{g}$ and 3.8 $\mathrm{m}^{2} / \mathrm{g}$ given by $\mathrm{BCAG}-\mathrm{NaOH}$ and $\mathrm{BCOP}-\mathrm{BM}$, respectively, the adsorption capacities of $\mathrm{BCAG}-\mathrm{NaOH}$ and $\mathrm{BCOP}-\mathrm{BM}$ were higher by 7.6 and $26.3 \mathrm{mg} / \mathrm{g}$ than CNT-modified BC (1\%), respectively. Moreover Dou and Jiang ${ }^{49}$ showed comparable adsorption capacity values of peanut shell (PS) and white clover (WC)-sodium humate ( $\mathrm{SH}$ )-modified $\mathrm{BC}$, with BCAG-NaOH. Despite the high $S_{\mathrm{BET}}$ values (Table 5), the results showed that the adsorption capacity of PS-SH-BC and WC-SH-BC was 3.1 $\mathrm{mg} / \mathrm{g}$ higher and $2.06 \mathrm{mg} / \mathrm{g}$ lower, respectively, compared to BAG-NaOH. Lyu et al. suggested that other than simple exposure of new surface sites might also be responsible for high adsorption. ${ }^{14}$ Indeed, they reported that the adsorption of $\mathrm{MeB}$ onto carbonaceous materials including $\mathrm{BC}$ and activated carbon is mainly controlled by two mechanisms: electrostatic interactions and $\pi-\pi$ interactions. ${ }^{48}$ The presence of these interactions was confirmed by FTIR, which explained the high removal efficiency of MeB shown by BCOP-BM and BCAG$\mathrm{NaOH}$ despite the low values of $S_{\mathrm{BET}}$.

Effect of Temperature and Thermodynamic Parameters. The thermodynamic parameter values of the adsorption of $\mathrm{MeB}$ onto different produced BCs were determined based on the corresponding plots (Figure 5d) and summarized in Table 4. The results showed that $\Delta G^{\circ}$ values were negative, which indicate that the adsorption of $\mathrm{MeB}$ by produced $\mathrm{BCs}$ was a 


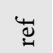

눙

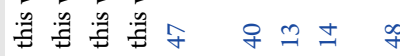

产急

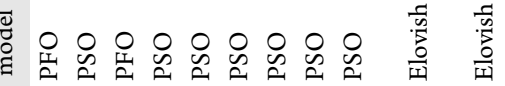

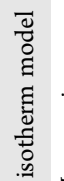

桊

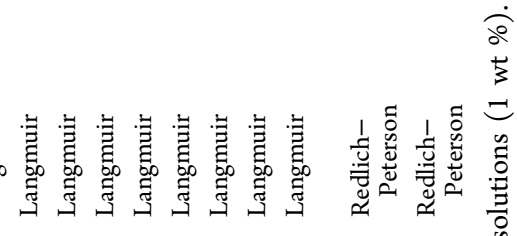

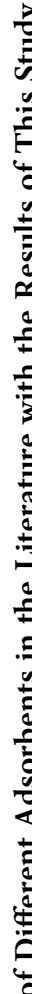

5ुำ

\& 0 के

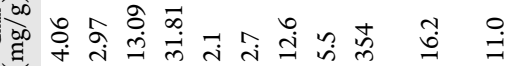

(a)

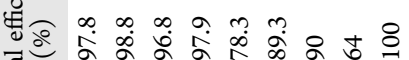

要

:

爮

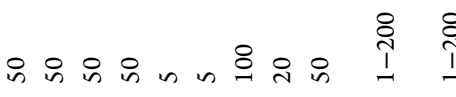

टँ

居羊实

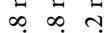

ヘิ

\& $\|$ I

D.

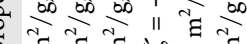

I

$\exists$

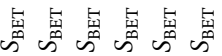

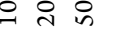

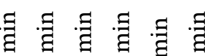

in $n$ in

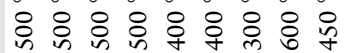

$\begin{array}{lll}0 & 0 \\ 0 & 0 \\ 8 & 8 \\ 0 & 0\end{array}$

spontaneous and feasible process. ${ }^{50} \Delta H^{\circ}$ values were positive except for BCAG-NaOH and BCAG-BM, which had negative values. A positive value of $\Delta H^{\circ}$ indicates that the process of adsorption was endothermic, while a negative value confirms the exothermic nature of the process. ${ }^{15}$ The randomness at the solid solution interface is evident by a positive $\Delta S^{\circ}$ value. ${ }^{51}$

Finally, a correlation matrix was applied (Figure 6) to confirm the relationship between the maximum adsorption capacity and

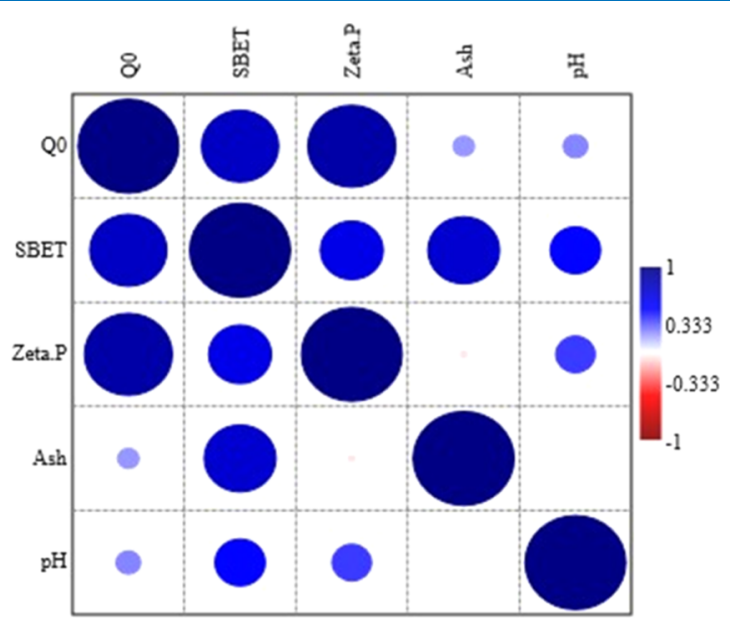

Figure 6. Correlation matrix between the maximum adsorption capacity $\left(Q_{0}\right)$ and the physicochemical and surface properties: specific surface area $\left(S_{\mathrm{BET}}\right), \zeta$-potential $(\zeta$-p), ash content (ash), and $\mathrm{pH}$. Positive correlations are presented in blue, and negative correlations are presented in red. Color intensity and circle size are proportional to the correlation coefficient $R$. On the right side of the correlogram, the legend color shows the correlation coefficients and the corresponding colors.

the physicochemical properties of BC. Maximum adsorption capacity $\left(Q_{0}\right)$ showed a strong positive correlation with $\zeta$ potential and $S_{\mathrm{BET}}$ with $R=0.872$ and 0.765 , respectively. The $\zeta$ potential represents the surface charge, which indicates the presence of negative functional groups confirmed previously by FTIR specifically for BCOP-BM. Despite the low values of $S_{\mathrm{BET}}$, the presence of oxygenic functional groups and aromatic rings promotes the adsorption capacity of $\mathrm{MeB}$ more than exposition of high surface area. ${ }^{14}$ In addition, $Q_{0}$ showed a weak correlation with ash content with $R=0.212$, which is in accordance with the study of Zhang et al. It was demonstrated that the adsorption capacity increased greatly on the de-ashed BC (removal of ash) compared with unactivated $\mathrm{BC}$, indicating that some organic sorption sites in the original $\mathrm{BC}$ were blocked or difficult to access due to their interactions with inorganic moiety (ash)..$^{52,53}$ The $\mathrm{pH}$ values showed a very weak correlation with the adsorption capacity with $R=0.245$, due to the high alkalinity of $\mathrm{BC}$ (raw and activated), which leads to neglecting the effect of $\mathrm{pH}$ on $Q_{0}$.

Figure 7 describes the proposed mechanism of $\mathrm{BC}$ activation and $\mathrm{MeB}$ adsorption on $\mathrm{BC}$ surface according to different results obtained in this study. The results confirm that ball milling activation increases the functional group on the $\mathrm{BC}$ surface and surface area compared to unactivated biochar (Figure 7). The presence of negative functional charge on the $\mathrm{BC}$ surface also increased the MeB adsorption on the $\mathrm{BC}$ surface (Figure 7). According to these results, the interaction between $\mathrm{BC}$ and $\mathrm{MeB}$ could be dominated by multiple mechanisms, mainly involving electrostatic and $\pi-\pi$ interactions ( $\pi$-electron donor-acceptor 


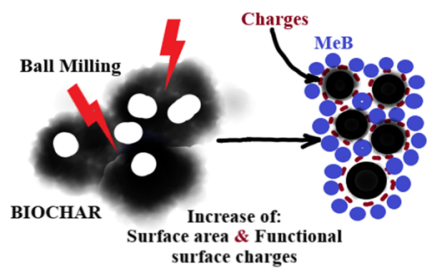

Figure 7. Biochar activation and the mechanism of $\mathrm{MeB}$ adsorption on biochar (BC).

interaction) and/or hydrophobic interactions more than the surface accessibility.

\section{CONCLUSIONS}

In this study, dry mechanochemical activation of biochars (BCs) derived from red macroalgae residue $(\mathrm{AG})$ and olive pomace (OP) for treating artificial textile wastewater containing the dye was investigated. The $\mathrm{BC}$ produced from $\mathrm{OP}$ and activated by $\mathrm{BM}$ showed the highest absolute value of $\zeta$-potential $(-59.7$ $\mathrm{mV}$ ) and high removal efficiency of methylene blue (MeB) compared to other activated BCs. The Langmuir isotherm model could well fit the adsorption process of MeB. The PFO model fitted the kinetic adsorption data of all biochars produced from $\mathrm{AG}$ and $\mathrm{BCOP}-\mathrm{NaOH}$, while the PSO model fitted the kinetic adsorption data of BCOP and BCOP-BM. The thermodynamic study showed that the adsorption process was spontaneous and endothermic except for BCAG- $\mathrm{NaOH}$ and BCAG-BM. The interaction between $\mathrm{BC}$ and $\mathrm{MeB}$ could be dominated by multiple mechanisms, mainly involving electrostatic and $\pi-\pi$ interactions ( $\pi$-electron donor-acceptor interaction) and/or hydrophobic interactions more than the surface accessibility.

\section{EXPERIMENTAL SECTION}

Feedstock. Red macroalgae residue (AG) and olive pomace (OP), two biomasses from Morocco, were used in this study. AG biomass (G. sesquipedale) was collected from an industrial processing of agar-agar extraction (SETEXAM Company, Kenitra, Morocco). OP was collected from a traditional press oil (Beni Mellal region, Morocco). AG and OP biomasses were grounded using a knife mill (SM100, Retsch, Germany) with a screen size of $4 \mathrm{~mm}$. Sodium hydroxide $(\mathrm{NaOH})$ was purchased from Sigma Aldrich (ref S8045).

Preparation of Activated Biochar (BC). Prior to the pyrolysis process, $100 \mathrm{~g}$ of each residue was chemically modified with $\mathrm{NaOH}(2.5$ wt \%). The solution was applied by a spray system at a solid loading of $1 \mathrm{~kg}$ TS/L. The choice of the catalyst type and concentration were based on our previous study. ${ }^{25}$ After $48 \mathrm{~h}$ of impregnation at room temperature, the chemically modified samples were dried at $105^{\circ} \mathrm{C}$ for $24 \mathrm{~h}$. The mechanical modification was carried out using a planetary ball mill (Pulverisette 7, Fritsch, Germany), and $50 \mathrm{~g}$ of each residue was placed in the planetary ball mill (BM) pot of $80 \mathrm{~mL}$ with 18 balls $(d=10 \mathrm{~mm})$ and milled at $800 \mathrm{rpm}$ for $1 \mathrm{~h}$. For pyrolysis process, a lab-scale horizontal stainless-steel fixed-bed reactor device developed at the INRAE IATE laboratory under operating conditions was adapted from previous studies. ${ }^{23,27}$ The purge gas (99.99\% pure nitrogen) was injected into the reactor at a flow rate varying between 250 and $260 \mathrm{~mL} / \mathrm{min}$. For each pretreated biomass, $15 \mathrm{~g}$ of each sample was loaded into a stainless-steel weigh boat and placed in the middle of the reactor to ensure homogenous pyrolysis. The reactor was then purged for $10 \mathrm{~min}$ before starting the pyrolysis to remove residual oxygen (air) from the reactor. Each sample was pyrolyzed at 500 ${ }^{\circ} \mathrm{C}$ with a heating rate of $10{ }^{\circ} \mathrm{C} / \mathrm{min}$ and a residence time of 15 $\mathrm{min}$ at the final temperature. The furnace was then cooled under nitrogen flow at $25^{\circ} \mathrm{C}$, and the yield of produced biochar (raw and modified) was calculated as follows

$$
Y(\%)=\frac{M_{\mathrm{BC}}(\mathrm{g})}{M_{\mathrm{s}}(\mathrm{g})} \times 100
$$

where $M_{\mathrm{BC}}$ and $M_{\mathrm{s}}$ represent the weights of the produced biochar and the initial dry mass of the sample, respectively. The $\mathrm{NaOH}$-activated BCs of AG and OP were named BCAG-NaOH and $\mathrm{BCOP}-\mathrm{NaOH}$, respectively, while the $\mathrm{BM}$-activated $\mathrm{BC}$ s of $A G$ and OP were named BCAG-BM and BCOP-BM (Figure 1), respectively. The raw BCs of AG and OP were named BCAG and $\mathrm{BCOP}$, respectively.

Physicochemical Properties of Residues and Produced Biochars. Ultimate, Proximate, and Fiber Analyses. The elemental compositions ( $\mathrm{C}, \mathrm{H}, \mathrm{N}, \mathrm{S})$ of different biomasses and biochars (BCs) were analyzed in duplicate using an elemental analyzer (VarioMicro V4.0.2, Elementar, Germany). The $\mathrm{H} / \mathrm{C}$ and $\mathrm{O} / \mathrm{C}$ molar ratios were calculated from elemental compositions. Carbohydrate and lignin contents of AG and OP biomasses were determined using the NREL protocol ${ }^{53}$ in which sugar concentrations were determined with HPLC analysis (Alliance System, Waters) according to the study of Barakat et al. ${ }^{54}$ All of the measurements were performed in triplicate. The proximate analysis of $\mathrm{AG}$ and $\mathrm{OP}$ and produced biochars was determined using a thermogravimetric analyzer (TGA 2-LF, Mettler Toledo, Switzerland). The determination method of moisture, volatile matter, fixed carbon, and ash content was reported in Tayibi et al. ${ }^{25}$ AG and OP biomasses and produced BCs were also characterized by an FTIR spectrometer (Bruker tensor 27, Bruker Optics) at wavelengths from 400 to $4000 \mathrm{~cm}^{-1}$ in transmittance mode at 16 scans.

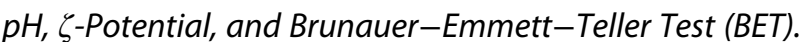
The $\mathrm{pH}$ values of $\mathrm{BC}$ were determined according to the study of Tayibi et al. $^{25}$ using a $\mathrm{pH}$ meter (FE20 FiveEasy, Mettler Toledo, Australia). The surface charge of BC was represented by the $\zeta$-potential, determined according to the study of Tayibi et al. ${ }^{25}$ using a modified protocol of Yao et al. ${ }^{55}$ The $\zeta$-potential was measured using a Nicomp dynamic light scattering system (Z3000, Entegris). The specific surface area was determined using $\mathrm{N}_{2}$-BET (3Flex, Micrometrics, Canada) analysis.

Adsorption Studies. Effect of Operational Parameters on $M e B$ Adsorption. The effects of different operational parameters (BC dose, contact time, $\mathrm{pH}$, initial $\mathrm{MeB}$ concentration, and temperature) were analyzed as follows:

- For the effect of the biochar dose, the experiment was carried out in $5 \mathrm{~mL}$ glass vials containing $1 \mathrm{~mL}$ of $50 \mathrm{mg} / \mathrm{L}$ of MeB solution $(\mathrm{pH}=7.4)$. The dose of biochar (raw or activated) varied between 10 and $50 \mathrm{~g} / \mathrm{L}$. The mixtures were stirred magnetically at $250 \mathrm{rpm}$ for $360 \mathrm{~min}$ at $25^{\circ} \mathrm{C}$.

- For the effect of $\mathrm{pH}$ on the adsorption of $\mathrm{MeB}$, the experiment was performed in $5 \mathrm{~mL}$ vials, introducing a volume of $1 \mathrm{~mL}$ of $50 \mathrm{mg} / \mathrm{L} \mathrm{MeB}$ solution and an optimal dose of biochar (brut or activated). The initial $\mathrm{pH}$ of the $\mathrm{MeB}$ solution was adjusted to values $2-12$ by the addition of $0.1 \mathrm{~mol} / \mathrm{L} \mathrm{HCL}$ or $0.1 \mathrm{~mol} / \mathrm{L} \mathrm{NaOH}$ solutions. The mixtures were magnetically stirred at $250 \mathrm{rpm}$ at $25^{\circ} \mathrm{C}$ for $360 \mathrm{~min}$. 
- For the kinetic study, the experiment of the effect of contact time was also carried out using $5 \mathrm{~mL}$ vials with a working volume of $1 \mathrm{~mL}$ of $\mathrm{MeB}$ solution $(50 \mathrm{mg} / \mathrm{L}, \mathrm{pH}=$ 7.4) and an optimal dose of each biochar (raw and activated), and the contact time varied between 0 and 760 $\mathrm{min}$. The mixtures were magnetically stirred at $250 \mathrm{rpm}$ at $25{ }^{\circ} \mathrm{C}$

- For the isotherm study, the effect of the initial $\mathrm{MeB}$ concentration was investigated, briefly, an optimal dose of each biochar (brut or activated) was introduced into $5 \mathrm{~mL}$ glass vials containing $1 \mathrm{~mL}$ of $\mathrm{MeB}$ solutions with different initial concentrations $(50-400 \mathrm{mg} / \mathrm{L})$. The mixtures were magnetically stirred at $250 \mathrm{rpm}$ at $25^{\circ} \mathrm{C}$ for $360 \mathrm{~min}$.

- For the thermodynamic study, the effect of temperature on the adsorption of $\mathrm{MeB}$ was performed; an optimal amount of each biochar was added to a set of $5 \mathrm{~mL}$ glass vials containing $1 \mathrm{~mL}$ of $50 \mathrm{mg} / \mathrm{L}$ of $\mathrm{MeB}$ solution and the reaction temperatures chosen were 25,40 , and $60{ }^{\circ} \mathrm{C}$.

All supernatants were collected and centrifuged at $8000 \mathrm{rpm}$ for $10 \mathrm{~min}$. The obtained solutions were filtered using $0.2 \mu \mathrm{m}$ filters and diluted to reach $1.5 \mathrm{~mL}$ for the analysis. The remaining $\mathrm{MeB}$ concentration was determined using a UVvisible spectrophotometer (7315, JENWAY, U.K.) at a wavelength of $664 \mathrm{~nm}$. The experiments were duplicate and only the average values were reported. The removal efficiency (\%) (eq 2), the adsorbed amount of $\mathrm{MeB}$ on BC at time $t, q_{t}(\mathrm{mg} / \mathrm{g})$ (eq 3$)$, and the amount of $\mathrm{MeB}$ adsorbed at equilibrium, $q_{\mathrm{e}}(\mathrm{mg} / \mathrm{g})$ (eq 4 ), were calculated using the following equations

$$
\begin{aligned}
& q_{t}=\left(C_{i}-C_{t}\right) \times V / w \\
& q_{\mathrm{e}}=\left(C_{i}-C_{\mathrm{e}}\right) \times V / w
\end{aligned}
$$$$
\text { removal efficiency }(\%)=\left(\left(C_{i}-C_{t}\right) / C_{i}\right) \times 100
$$

where $C_{i}(\mathrm{mg} / \mathrm{L})$ is the initial $\mathrm{MeB}$ concentration, $C_{t}(\mathrm{mg} / \mathrm{L})$ is the $\mathrm{MeB}$ concentration at time $t(\mathrm{~min}), C_{\mathrm{e}}(\mathrm{mg} / \mathrm{L})$ is the $\mathrm{MeB}$ concentration at equilibrium, $V(\mathrm{~L})$ is the volume of $\mathrm{MeB}$ solution, and $w(\mathrm{~g})$ is the weight of the adsorbent.

Kinetic Models. To analyze the adsorption kinetic process of all studied biochars (raw and activated), the nonlinear pseudofirst-order (PFO), nonlinear pseudo-second-order (PSO), and intraparticle diffusion models (ID) were applied. The nonlinear forms of PFO (eq 5), ${ }^{56}$ PSO (eq 6), ${ }^{56}$ and the ID (eq 7) ${ }^{41}$ models are expressed in the following equations

$$
\begin{aligned}
& q_{t}=\left(q_{\mathrm{e}}-\mathrm{e}^{-K_{1} t}\right) \\
& q_{t}=K_{2} q_{\mathrm{e}}^{2} t / 1+K_{2} q_{\mathrm{e}} t \\
& q_{t}=k_{\mathrm{p}} t^{1 / 2}+C
\end{aligned}
$$

where $q_{\mathrm{e}}(\mathrm{mg} / \mathrm{g})$ is the adsorption capacity at equilibrium; $q_{t}$ $(\mathrm{mg} / \mathrm{g})$ is the adsorption capacity at contact time $t(\mathrm{~min}) ; K_{1}$ $\left(\min ^{-1}\right), K_{2}(\mathrm{~g} /(\mathrm{mg} \min ))$, and $K_{\mathrm{p}}\left(\mathrm{g} /\left(\mathrm{mg} \mathrm{min}{ }^{1 / 2}\right)\right)$ are the equilibrium rate constants for PFO, PSO, and ID models, respectively; and $\mathrm{C}$ is a constant.

The normalized standard deviation $\Delta q(\%)$ (eq 8) was applied to confirm the applicability of the kinetic model and is defined as follows

$$
\Delta q(\%)=100 \times \sqrt{\sum\left[\left(q_{\exp }-q_{\text {cal }}\right) / q_{\text {exp }}\right]^{2} / N-1}
$$

where $N$ is the number of data points and $q_{\text {exp }}$ and $q_{\text {cal }}(\mathrm{mg} / \mathrm{g})$ are the experimental and calculated adsorption capacities, respectively.

The Marquardt's percentage standard deviation (MPSD) $)^{57}$ (eq 9) was applied to evaluate the applicability of isotherm models, and it is defined in the following equation

$$
\operatorname{MPSD}=100 \times \sqrt{\left.\frac{1}{p-n} \sum_{i=1}^{p}\left(q_{\mathrm{e}, \exp }-q_{\mathrm{e}, \mathrm{cal}}\right) / q_{\mathrm{e}, \exp }\right)^{2}}
$$

where $q_{\mathrm{e} \text { exp }}(\mathrm{mg} / \mathrm{g})$ and $q_{\mathrm{e}, \mathrm{cal}}(\mathrm{mg} / \mathrm{g})$ are the experimental and calculated adsorption capacities at equilibrium, respectively.

Equilibrium Isotherm Study. In this study, Langmuir and Freundlich isotherm models were used to determine the maximum adsorption capacity and mechanism. ${ }^{58}$ The nonlinear form of the Langmuir isotherm model (eq 10) is expressed as

$$
q_{\mathrm{e}}=Q_{0} K_{\mathrm{L}} C_{\mathrm{e}} /\left(1+K_{\mathrm{L}} C_{\mathrm{e}}\right)
$$

where $K_{\mathrm{L}}$ reflects the solute adsorptivity $(\mathrm{L} / \mathrm{g})$ and $\mathrm{Q}_{0}$ is the Langmuir adsorption capacity $(\mathrm{mg} / \mathrm{g})$.

A dimensionless separation factor $\left(R_{\mathrm{L}}\right)$ can be defined based on the Langmuir isotherm and expressed as

$$
R_{\mathrm{L}}=1 /\left(1+K_{\mathrm{L}} C_{0}\right)
$$

where $C_{0}$ and $K_{\mathrm{L}}$ are the initial $\mathrm{MeB}$ concentration and the Langmuir constant, respectively.

The nonlinear form of the Freundlich model is expressed as

$$
q_{\mathrm{e}}=K_{\mathrm{F}} C_{\mathrm{e}}^{b_{\mathrm{F}}}
$$

where $K_{\mathrm{F}}$ reflects the adsorbent capacity $(\mathrm{L} / \mathrm{g})$ and $b_{\mathrm{F}}$ is the heterogeneity factor (unitless) ranging from 0 to 1 .

Thermodynamic Study. To investigate the adsorption thermodynamics of $\mathrm{MeB}$ adsorption onto raw and activated biochars, Gibbs free energy $\Delta G^{\circ}(\mathrm{kJ} / \mathrm{mol})$, enthalpy $\Delta H^{\circ}(\mathrm{kJ} /$ $\mathrm{mol})$, and entropy $\Delta S(\mathrm{~J} /(\mathrm{mol} \mathrm{K}))$ were calculated in the following equations reported by Fan et al., ${ }^{40}$ respectively

$$
\begin{aligned}
& \Delta G^{\circ}=-R T \ln \left(K_{\mathrm{d}}\right) \\
& \ln K_{\mathrm{d}}=\Delta S^{\circ} / R-\Delta H^{\circ} / R T
\end{aligned}
$$

where $R(8.314 \mathrm{~J} /(\mathrm{mol} \mathrm{K}))$ is the universal gas constant, $T(\mathrm{~K})$ is the absolute solution temperature, and $K_{\mathrm{d}}$ is the distribution coefficient which can be calculated as

$$
K_{\mathrm{d}}=C_{\mathrm{Ae}} / C_{\mathrm{e}}
$$

where $C_{\mathrm{Ae}}(\mathrm{mg} / \mathrm{L})$ is the amount adsorbed on a solid at equilibrium and $C_{\mathrm{e}}(\mathrm{mg} / \mathrm{L})$ is the equilibrium concentration.

Data Analyses. Analysis of variance (ANOVA) was performed using the $\mathrm{R}$ version 3.4.4. The effects of chemical and mechanical modifications on the $\mathrm{BC}$ yield, $\mathrm{pH}, \zeta$-potential, and specific surface area were tested by one-way ANOVA. Correlations between $\mathrm{BC}$ properties and adsorption capacities were analyzed using a correlation matrix using PAST.3 (Paleontological Statistics Software Package for Education and Data Analysis) software.

\section{ASSOCIATED CONTENT}

\section{SI Supporting Information}

The Supporting Information is available free of charge at https://pubs.acs.org/doi/10.1021/acsomega.0c04020. 
Fourier transform infrared (FTIR) spectroscopic spectra (Figure S1) of the residues and their raw and activated biochars; effect of dose concentrations of different produced biochars on removal efficiency and adsorption capacity (Figure S2); and nonlinear fit of the kinetic models of $\mathrm{MeB}$ adsorption on different produced biochars (Figure S3) (PDF)

\section{AUTHOR INFORMATION}

\section{Corresponding Author}

Abdellatif Barakat - IATE, Montpellier University, INRAE, Agro Institut, 34060 Montpelier, France; 이이이.org/00000003-4196-4351; Email: Abdellatif.barakat@inrae.fr

\section{Authors}

Saida Tayibi - IATE, Montpellier University, INRAE, Agro Institut, 34060 Montpelier, France; Mohammed VI Polytechnic University (UM6P), 43150 Ben Guerir, Morocco; APESA, Pôle Valorisation, 64053 Lescar, France; LIMAT, Faculté des Sciences Ben M'Sik, Université Hassan II de, 20670 Casablanca, Morocco

Florian Monlau - APESA, Pôle Valorisation, 64053 Lescar, France

Nour-Elhouda Fayoud - IATE, Montpellier University, INRAE, Agro Institut, 34060 Montpelier, France; Mohammed VI Polytechnic University (UM6P), 43150 Ben Guerir, Morocco

Emna Abdeljaoued - IATE, Montpellier University, INRAE, Agro Institut, 34060 Montpelier, France; Mohammed VI Polytechnic University (UM6P), 43150 Ben Guerir, Morocco

Hassane Hannache - Mohammed VI Polytechnic University (UM6P), 43150 Ben Guerir, Morocco; LIMAT, Faculté des Sciences Ben M'Sik, Université Hassan II de, 20670 Casablanca, Morocco

Youssef Zeroual - Situation Innovation, OCP Group, BP 118 El Jadida, Morocco

Abdallah Oukarroum - Mohammed VI Polytechnic University (UM6P), 43150 Ben Guerir, Morocco

Complete contact information is available at:

https://pubs.acs.org/10.1021/acsomega.0c04020

\section{Notes}

The authors declare no competing financial interest.

This article does not contain any studies with human participants or animals performed by any of the authors.

\section{ACKNOWLEDGMENTS}

The authors would like to thank the SETEXAM Company in Morocco for providing the macroalgae residue. This work was based on a formal collaboration financed by ATLASS Project (OCP group, INRAE Montpellier, Mohammed VI Polytechnic University and APESA technological center) and ANR Pyrodigest (Arimnet 2).

\section{REFERENCES}

(1) Li, X. Y.; Han, D.; Xie, J. F.; Wang, Z. B.; Gong, Z. Q.; Li, B. Hierarchical Porous Activated Biochar Derived from Marine Macroalgae Wastes (Enteromorpha Prolifera): Facile Synthesis and Its Application on Methylene Blue Removal. RSC Adv. 2018, 8, 2923729247.

(2) Ji, B.; Wang, J.; Song, H.; Chen, W. Removal of Methylene Blue from Aqueous Solutions Using Biochar Derived from a Fallen Leaf by
Slow Pyrolysis: Behavior and Mechanism. J. Environ. Chem. Eng. 2019, 7, No. 103036.

(3) Dou, G.; Jiang, Z. Preparation of Sodium Humate-Modified Biochar Absorbents for Water Treatment. Am. Chem. Soc. Omega 2019, 4, 16536-16542.

(4) Kim, T. H.; Park, C.; Kim, S. Water Recycling from Desalination and Purification Process of Reactive Dye Manufacturing Industry by Combined Membrane Filtration. J. Clean. Prod. 2005, 13, 779-786.

(5) Chakrabarti, S.; Dutta, B. K. Photocatalytic Degradation of Model Textile Dyes in Wastewater Using $\mathrm{ZnO}$ as Semiconductor Catalyst. J. Hazard. Mater. 2004, 112, 269-278.

(6) Maneerung, T.; Liew, J.; Dai, Y.; Kawi, S.; Chong, C.; Wang, C. H. Activated Carbon Derived from Carbon Residue from Biomass Gasification and Its Application for Dye Adsorption: Kinetics, Isotherms and Thermodynamic Studies. Bioresour. Technol. 2016, 200, 350-359.

(7) González, M. E.; Cea, M.; Sangaletti, N.; González, A.; Toro, C.; Diez, M. C.; Moreno, N.; Querol, X.; Navia, R. Biochar Derived from Agricultural and Forestry Residual Biomass: Characterization and Potential Application for Enzymes Immobilization. J. Biobased Mater. Bioenergy 2013, 7, 724-732.

(8) Bahng, M. K.; Mukarakate, C.; Robichaud, D. J.; Nimlos, M. R. Current Technologies for Analysis of Biomass Thermochemical Processing: A Review. Anal. Chim. Acta 2009, 651, 117-138.

(9) Gul, S.; Whalen, J. K.; Thomas, B. W.; Sachdeva, V.; Deng, H. Physico-Chemical Properties and Microbial Responses in BiocharAmended Soils: Mechanisms and Future Directions. Agric. Ecosyst. Environ. 2015, 206, 46-59.

(10) Li, H.; Deng, Q.; Chen, H.; Zheng, J.; Zhong, Y.; Zhang, P.; Wang, J.; Zeng, Z.; Deng, S. Benzenesulfonic Acid Functionalized Hydrophobic Mesoporous Biochar as an Efficient Catalyst for the Production of Biofuel. Appl. Catal., A 2019, 580, No. 178.

(11) Inyang, M.; Dickenson, E. The Potential Role of Biochar in the Removal of Organic and Microbial Contaminants from Potable and Reuse Water: A Review. Chemosphere 2015, 134, 232-240.

(12) Wang, J.; Wang, S. Preparation, Modification and Environmental Application of Biochar: A Review. J. Clean. Prod 2019, 227, No. 1002.

(13) Inyang, M.; Gao, B.; Zimmerman, A.; Zhang, M.; Chen, H. Synthesis, Characterization, and Dye Sorption Ability of Carbon Nanotube-Biochar Nanocomposites. Chem. Eng. J. 2014, 236, 39-46.

(14) Lyu, H.; Gao, B.; He, F.; Zimmerman, A. R.; Ding, C.; Huang, H.; Tang, J. Effects of Ball Milling on the Physicochemical and Sorptive Properties of Biochar: Experimental Observations and Governing Mechanisms. Environ. Pollut. 2018, 233, 54-63.

(15) Ahmed, M. J. Application of Agricultural Based Activated Carbons by Microwave and Conventional Activations for Basic Dye Adsorption: Review. J. Environ. Chem. Eng. 2016, 4, 89-99.

(16) Ding, Z.; Hu, X.; Wan, Y.; Wang, S.; Gao, B. Removal of Lead, Copper, Cadmium, Zinc, and Nickel from Aqueous Solutions by AlkaliModified Biochar: Batch and Column Tests. J. Ind. Eng. Chem. 2016, 33, 239-245.

(17) Hou, J.; Liu, Y.; Wen, S.; Li, W.; Liao, R.; Wang, L. SorghumWaste-Derived High-Surface Area $\mathrm{KOH}$-Activated Porous Carbon for Highly Efficient Methylene Blue and Pb(II) Removal. Am. Chem. Soc. Omega 2020, 5, 13548-13556.

(18) Jin, H.; Capareda, S.; Chang, Z.; Gao, J.; Xu, Y.; Zhang, J. Biochar Pyrolytically Produced from Municipal Solid Wastes for Aqueous As (V) Removal: Adsorption Property and Its Improvement with $\mathrm{KOH}$ Activation. Bioresour. Technol. 2014, 169, 622-629.

(19) Sun, K.; Tang, J.; Gong, Y.; Zhang, H. Characterization of Potassium Hydroxide ( $\mathrm{KOH})$ Modified Hydrochars from Different Feedstocks for Enhanced Removal of Heavy Metals from Water. Environ. Sci. Pollut. Res. 2015, 22, 16640-16651.

(20) Wei, X.; Wang, X.; Gao, B.; Zou, W.; Dong, L. Facile Ball-Milling Synthesis of $\mathrm{CuO} /$ Biochar Nanocomposites for Efficient Removal of Reactive Red 120. Am. Chem. Soc. Omega 2020, 5, 5748-5755.

(21) Wang, B.; Gao, B.; Wan, Y. Comparative Study of Calcium Alginate, Ball-Milled Biochar, and Their Composites on Aqueous 
Methylene Blue Adsorption. Environ. Sci. Pollut. Res. 2019, 26, 1153511541 .

(22) Ainane, T. Valuation Algal Biomass of Morocco:Potential Pharmacological and Environmental Applications, Case of the Brown Algae Cystoseira Tamariscifolia and Bifurcaria Bifurcate; Faculté des Sciences Ben M'sik Université Hassan II Casablanca, 2011.

(23) Aboulkas, A.; Hammani, H.; El Achaby, M.; Bilal, E.; Barakat, A.; El harfi, K. Valorization of Algal Waste via Pyrolysis in a Fixed-Bed Reactor: Production and Characterization of Bio-Oil and Bio-Char. Bioresour. Technol. 2017, 243, 400-408.

(24) U.S. Department of Agriculture. Morocco-Production of Olive Oil, 2019. https://www.nationmaster.com/nmx/timeseries/moroccoproduction-of-olive-oil.

(25) Tayibi, S.; Monlau, F.; Oukarroum, A.; Zeroual, Y. One-Pot Activation and Pyrolysis of Moroccan Gelidium sesquipedale Red Macroalgae Residue: Production of an Efficient Adsorbent Biochar. Biochar 2019, 1, 401-412.

(26) Dehkhoda, A. M.; Gyenge, E.; Ellis, N. A Novel Method to Tailor the Porous Structure of KOH-Activated Biochar and Its Application in Capacitive Deionization and Energy Storage. Biomass Bioenergy 2016, 87, No. 107

(27) Francavilla, M.; Manara, P.; Kamaterou, P.; Monteleone, M.; Zabaniotou, A. Cascade Approach of Red Macroalgae Gracilaria Gracilis Sustainable Valorization by Extraction of Phycobiliproteins and Pyrolysis of Residue. Bioresour. Technol. 2014, 184, 305-313.

(28) Windeatt, J. H.; Ross, A. B.; Williams, P. T.; Forster, P. M.; Nahil, M. A.; Singh, S. Characteristics of Biochars from Crop Residues: Potential for Carbon Sequestration and Soil Amendment. J. Environ. Manage. 2014, 146, 189-197.

(29) Manyà, J. J.; Laguarta, S.; Ortigosa, M. A. Study on the Biochar Yield and Heat Required during Pyrolysis of Two-Phase Olive Mill Waste. Energy Fuels 2013, 27, 5931-5939.

(30) Aghababaei, A.; Ncibi, M. C.; Sillanpää, M. Optimized Removal of Oxytetracycline and Cadmium from Contaminated Waters Using Chemically-Activated and Pyrolyzed Biochars from Forest and WoodProcessing Residues. Bioresour. Technol. 2017, 239, 28-36.

(31) Linville, J. L.; Shen, Y.; Ignacio-de Leon, P. A.; Schoene, R. P.; Urgun-Demirtas, M. In-Situ Biogas Upgrading during Anaerobic Digestion of Food Waste Amended with Walnut Shell Biochar at Bench Scale. Waste Manage. Res. 2017, 35, 669-679.

(32) Poo, K. M.; Son, E. B.; Chang, J. S.; Ren, X.; Choi, Y. J.; Chae, K. J. Biochars Derived from Wasted Marine Macro-Algae (Saccharina Japonica and Sargassum Fusiforme) and Their Potential for Heavy Metal Removal in Aqueous Solution. J. Environ. Manage. 2018, 206, 364-372.

(33) Yuan, J. H.; Xu, R. K.; Zhang, H. The Forms of Alkalis in the Biochar Produced from Crop Residues at Different Temperatures. Bioresour. Technol. 2011, 102, 3488-3497.

(34) Peterson, S. C.; Jackson, M. A.; Kim, S.; Palmquist, D. E. Increasing Biochar Surface Area: Optimization of Ball Milling Parameters. Powder Technol 2012, 228, 115-120.

(35) Ahmed, M. B.; Zhou, J. L.; Ngo, H. H.; Guo, W. Insight into Biochar Properties and Its Cost Analysis. Biomass Bioenergy 2016, 84, 76-86.

(36) Zhang, Y. J.; Xing, Z. J.; Duan, Z. K.; Li, M.; Wang, Y. Effects of Steam Activation on the Pore Structure and Surface Chemistry of Activated Carbon Derived from Bamboo Waste. Appl. Surf. Sci. 2014, $315,279-286$.

(37) Li, B.; Yang, L.; Wang, C. Q.; Zhang, Q. P.; Liu, Q. C.; Li, Y. D.; Xiao, R. Adsorption of Cd(II) from Aqueous Solutions by Rape Straw Biochar Derived from Different Modification Processes. Chemosphere 2017, 175, No. 322

(38) Lee, Y.; Park, J.; Ryu, C.; Gang, K. S.; Yang, W.; Park, Y. K.; Jung, J.; Hyun, S. Comparison of Biochar Properties from Biomass Residues Produced by Slow Pyrolysis at $500{ }^{\circ}$ C. Bioresour. Technol. 2013, 148, 196-201.

(39) Zhu, Y.; Yi, B.; Yuan, Q.; Wu, Y.; Wanga, M. Removal of Methylene Blue from Aqueous Solution by Cattle Manure-Derived Low Temperature Biochar. RSC Adv 2018, 8, 19917-19929.
(40) Fan, S.; Tang, J.; Wang, Y.; Li, H.; Zhang, H.; Tang, J.; Wang, Z.; $\mathrm{Li}, \mathrm{X}$. Biochar Prepared from Co-Pyrolysis of Municipal Sewage Sludge and Tea Waste for the Adsorption of Methylene Blue from Aqueous Solutions: Kinetics, Isotherm, Thermodynamic and Mechanism. J. Mol. Liq. 2016, 220, 432-441.

(41) Sun, L.; Dongmei, C.; Shungang, W.; Zebin, Y. Performance, Kinetic, and Equilibrium of Methylene Blue Adsorption on Biochar Derived from Eucalyptus Saw Dust Modified with Citric, Tartaric, and Acetic Acids. Bioresour. Technol 2015, 198, 300-308.

(42) Fu, J.; Chen, Z.; Wang, M.; Liu, S.; Zhang, J.; Zhang, J.; Han, R.; $\mathrm{Xu}, \mathrm{Q}$. Adsorption of Methylene Blue by a High-Efficiency Adsorbent (Polydopamine Microspheres): Kinetics, Isotherm, Thermodynamics and Mechanism Analysis. Chem. Eng. J. 2015, 259, 53-61.

(43) López-luna, J.; Ramírez-montes, L. E.; Martinez-vargas, S.; Martínez, A. I.; Mijangos-ricardez, O. F.; González-chávez, M. C. A.; Carrillo-gonzález, R.; Solís-domínguez, F. A.; Cuevas-díaz, M. C.; Vázquez-hipólito, V. Linear and Nonlinear Kinetic and Isotherm Adsorption Models for Arsenic Removal by Manganese Ferrite Nanoparticles. SN Appl. Sci. 2019, 1, No. 950.

(44) Kumar, K. V. Linear and Non-Linear Regression Analysis for the Sorption Kinetics of Methylene Blue onto Activated Carbon. J. Hazard. Mater. 2006, 137, 1538-1544.

(45) Guo, J. Z.; Li, B.; Liu, L.; Lv, K. Removal of Methylene Blue from Aqueous Solutions by Chemically Modified Bamboo. Chemosphere 2014, 111, 225-231.

(46) Yang, G.; Wu, L.; Xian, Q.; Shen, F.; Wu, J.; Zhang, Y. Removal of Congo Red and Methylene Blue from Aqueous Solutions by Vermicompost- Derived Biochars. PLoS One 2016, 11, No. e0154562.

(47) Sun, L.; Wan, S.; Luo, W. Biochars Prepared from Anaerobic Digestion Residue, Palm Bark, and Eucalyptus for Adsorption of Cationic Methylene Blue Dye: Characterization, Equilibrium, and Kinetic Studies. Bioresour. Technol. 2013, 140, 406-413.

(48) Lyu, H.; Gao, B.; He, F.; Zimmerman, A. R.; Ding, C.; Tang, J.; Crittenden, J. C. Experimental and Modeling Investigations of BallMilled Biochar for the Removal of Aqueous Methylene Blue. Chem. Eng. J. 2018, 335, 110-119.

(49) Dou, G.; Jiang, Z. Preparation of Sodium Humate-Modified Biochar Absorbents for Water Treatment. ACS Omega 2019, 4, 1653616542.

(50) Fan, S.; Wang, Y.; Wang, Z.; Tang, J.; Tang, J.; Li, X. Removal of Methylene Blue from Aqueous Solution by Sewage Sludge-Derived Biochar: Adsorption Kinetics, Equilibrium, Thermodynamics and Mechanism. J. Environ. Chem. Eng. 2017, 5, 601-611.

(51) Mishra, A. K.; Shahi, V. K.; Agrawal, N. R.; Das, I. Synthesis, Characterization, and Application of a Thiophene-Pyrrole Copolymer As an Efficient Adsorbent for Removal of Methylene Blue. J. Chem. Eng. Data 2018, 63, 3206-3214.

(52) Zhang, P.; Sun, H.; Yu, L.; Sun, T. Adsorption and Catalytic Hydrolysis of Carbaryl and Atrazine on Pig Manure-Derived Biochars: Impact of Structural Properties of Biochars. J. Hazard. Mater. 2013, 244-245, 217-224.

(53) Sluiter, A.; Hames, B.; Ruiz, R.; Scarlata, C.; Sluiter, J.; Templeton, D.; Crocker, D. Determination of Structural Carbohydrates and Lignin in Biomass, Tech. Rep. NREL/TP-510-42618; Laboratory Analytical Procedure (LAP), 2008; pp 1-15.

(54) Barakat, A.; Monlau, F.; Solhy, A.; Carrere, H. Mechanical Dissociation and Fragmentation of Lignocellulosic Biomass: Effect of Initial Moisture, Biochemical and Structural Proprieties on Energy Requirement. Appl. Energy 2015, 142, 240-246.

(55) Yao, Y.; Gao, B.; Inyang, M.; Zimmerman, A. R.; Cao, X.; Pullammanappallil, P.; Yang, L. Biochar Derived from Anaerobically Digested Sugar Beet Tailings: Characterization and Phosphate Removal Potential. Bioresour. Technol. 2011, 102, 6273-6278.

(56) Jun, L. Y.; Karri, R. R.; Mubarak, N. M.; Yon, L. S.; Bing, C. H.; Khalid, M.; Jagadish, P.; Abdullah, E. C. Modelling of Methylene Blue Adsorption Using Peroxidase Immobilized Functionalized Buckypaper/Polyvinyl Alcohol Membrane via Ant Colony Optimization. Environ. Pollut. 2020, 259, No. 113940. 
(57) Paluri, P.; Ahmad, K. A.; Durbha, K. S. Importance of Estimation of Optimum Isotherm Model Parameters for Adsorption of Methylene Blue onto Biomass Derived Activated Carbons: Comparison between

Linear and Non-Linear Methods. Biomass Conv. Bioref. 2020, 209, No. 172.

(58) Banerjee, P.; Das, P.; Zaman, A.; Das, P. Application of Graphene Oxide Nanoplatelets for Adsorption of Ibuprofen from Aqueous Solutions: Evaluation of Process Kinetics and Thermodynamics. Process Saf. Environ. Prot. 2016, 101, 45-53. 